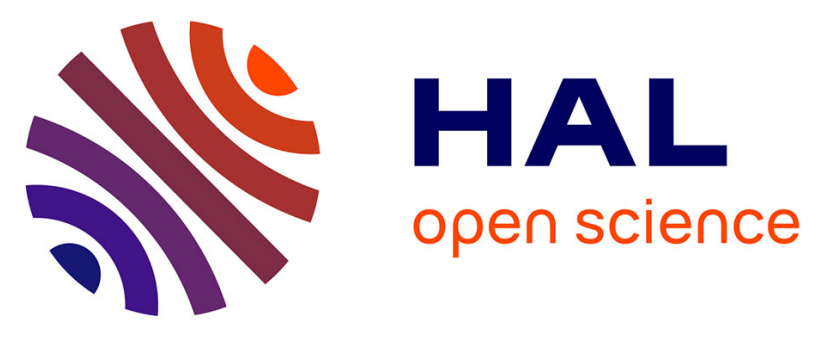

\title{
Will Sulfide Electrolytes be Suitable Candidates for Constructing a Stable Solid/Liquid Electrolyte Interface?
}

Bo Fan, Yanghai Xu, Rui Ma, Zhongkuan Luo, Fang Wang, Xianghua Zhang, Hongli Ma, Ping Fan, Bai Xue, Weiqiang Han

\section{To cite this version:}

Bo Fan, Yanghai Xu, Rui Ma, Zhongkuan Luo, Fang Wang, et al.. Will Sulfide Electrolytes be Suitable Candidates for Constructing a Stable Solid/Liquid Electrolyte Interface?. ACS Applied Materials \& Interfaces, 2020, 12 (47), pp.52845-52856. 10.1021/acsami.0c16899 . hal-03037741

\section{HAL Id: hal-03037741 https://hal.science/hal-03037741}

Submitted on 18 Dec 2020

HAL is a multi-disciplinary open access archive for the deposit and dissemination of scientific research documents, whether they are published or not. The documents may come from teaching and research institutions in France or abroad, or from public or private research centers.
L'archive ouverte pluridisciplinaire $\mathbf{H A L}$, est destinée au dépôt et à la diffusion de documents scientifiques de niveau recherche, publiés ou non, émanant des établissements d'enseignement et de recherche français ou étrangers, des laboratoires publics ou privés. 


\section{Will Sulfide Electrolytes be Suitable Candidates for Constructing Stable Solid/liquid Electrolyte Interface?}

Bo Fan ${ }^{\mathrm{a} \&}$, Yanghai $\mathrm{Xu}^{\mathrm{a} \&}$, Rui $\mathrm{Ma}^{\mathrm{b}}$, Zhongkuan Luo ${ }^{\mathrm{b}}$, Fang Wang ${ }^{\mathrm{b}}$, Xianghua Zhang, Hongli $\mathrm{Ma}^{\mathrm{c}}$, Ping Fan ${ }^{\mathrm{a}}$, Bai Xue ${ }^{\mathrm{a} *}$ and Weiqiang Han ${ }^{\mathrm{d} *}$

${ }^{a}$ Shenzhen Key Laboratory of Advanced Thin Films and Applications, College of Physics and Optoelectronic Engineering, Shenzhen University, Shenzhen, 518060, China

${ }^{\mathrm{b}}$ College of Chemistry and Environmental Engineering, Shenzhen University, Shenzhen, 518060, China

${ }^{\mathrm{c}}$ Univ Rennes, CNRS, ISCR (Institut des Sciences Chimiques de Rennes) - UMR 6226, Rennes 35042, France

${ }^{d}$ School of Materials Science and Engineering, Zhejiang University, Hangzhou, 310007, China

\& These authors contributed equally to this work as co-first authors.

* Corresponding author.E-mail address:baixue@szu.edu.cn, hanwq@zju.edu.cn

Keywords: hybrid electrolytes, interfacial stability, liquid phase synthesis, lithium thiophosphates, lithium-sulfur batteries

\section{ABSTRACT}

Conversion-type batteries with electrode materials partially dissolved in liquid electrolyte exhibit high specific capacity and excellent redox kinetics, but currently poor stability due to the shuttle effect. Using solid-electrolyte separator to block the mass exchange between cathode and anode can eliminate the shuttle effect. A stable interface between the solid-electrolyte separator and the liquid electrolyte is essential for the battery performance. Here we demonstrate that a stable interface with low interfacial resistance and limited side reactions can be formed between the sulfide solid electrolyte $\beta$ - $\mathrm{Li}_{3} \mathrm{PS}_{4}$ and the widely used ether-based liquid electrolytes, under both reduction and oxidation conditions, due to the rapid formation of an effective protective layer of ether-solvated $\mathrm{Li}_{3} \mathrm{PS}_{4}$ at the sulfide/liquid electrolyte interface. This discovery has inspired the design of a $\beta$ - $\mathrm{Li}_{3} \mathrm{PS}_{4}$ coated-solid electrolyte $\mathrm{Li}_{7} \mathrm{P}_{3} \mathrm{~S}_{11}$ separator with 
simultaneously high ion conduction ability and good interfacial stability with liquid electrolyte, so that hybrid Li-S batteries with this composite separator conserve high discharge capacity of $1047 \mathrm{~mA} \mathrm{~h} \mathrm{~g}^{-1}$ and high $2^{\text {nd }}$ discharge plateau of $2.06 \mathrm{~V}$ after 150 cycles.

\section{INTRODUCTION}

The development of new energy source technologies such as electric vehicles, solar and wind power stations, requires high-performance rechargeable batteries with high energy density and excellent cycling performance. ${ }^{1}$ Intercalation battery is one of the most intensively studied rechargeable batteries. The most successful intercalation battery, the lithium-ion battery, which currently dominates the rechargeable battery market and shows great potential to realize all-solid-state form, ${ }^{2-3}$ is however limited by the unsatisfactory theoretical energy density. Developing novel solid electrode materials with simultaneously high energy density and excellent ion mobility is proven an arduous task. For example, the Chevrel phase cathodes for $\mathrm{Mg}$ batteries like $\mathrm{Mg}_{\mathrm{x}} \mathrm{Mo}_{3} \mathrm{~S}_{4}$ show excellent $\mathrm{Mg}^{2+}$ mobility, but their theoretical energy density is low. ${ }^{4-}$ ${ }^{5}$ Sulfur cathode in all-solid-state lithium-sulfur batteries has excellent specific capacity of $1672 \mathrm{~mA} \mathrm{~h} \mathrm{~g}^{-1}$, but its lithium diffusion coefficient is extremely low, leading to the large overpotential of the batteries. ${ }^{6-7}$ Conversion battery is another widely studied type of rechargeable batteries. With delicate and appropriate conception, the electrode materials of conversion-type batteries can be partially dissolved in the liquid electrolyte so that the redox kinetics is dramatically improved. With this strategy, conversion 
batteries such as $\mathrm{Li}-\mathrm{S},{ }^{8} \mathrm{Li}_{-} \mathrm{O}_{2}$ (air), ${ }^{9} \mathrm{Mg}-\mathrm{X}(\mathrm{X}=\mathrm{Br}, \mathrm{I}),{ }^{10-11} \mathrm{Mg}-\mathrm{S},{ }^{12} \mathrm{Al}-\mathrm{S},{ }^{13}$ etc., have been fabricated and usually show higher energy density and better rate performance than their intercalation counterparts. However, the dissolution of electrodes in the electrolyte triggers the cross-talk between cathode and anode, and this induces shuttle effect and impairs the cycling stability of the batteries. This phenomenon is one of the key issues of the intensively studies Li-S batteries, ${ }^{14-16}$ and it is also responsible for the cycling performance deterioration of the multivalence ion batteries under active development. ${ }^{10-13}$

If the diffusion of the active materials is well limited, then constructing conversion batteries with soluble electrode materials will be a promising way to develop highperformance rechargeable batteries, as demonstrated by the intensive research activities on Li-S batteries during the past decade. ${ }^{17-21}$ Physically separating the anode and the cathode with an ion-conductive solid-electrolyte (SE) separator/interlayer is considered to be an effective strategy to cut off the cross-talk between the electrodes, which has been successfully demonstrated in the hybrid Li-S batteries where coulombic efficiency of $100 \%$ is achieved due to the inhibition of shuttle effect. ${ }^{22-23}$ Additionally and importantly, using this SE separator/interlayer decouples the anodic and cathodic requirements for the electrolyte, providing a new avenue of electrolyte design for novel rechargeable batteries such as Li-air batteries, ${ }^{24} \mathrm{Mg}$ batteries, ${ }^{25}$ etc. .

Note that the introduction of SE separator/interlayer structure into batteries creates a new interface between solid and liquid electrolytes. Like other interfaces in batteries, 
the stability of this solid/liquid electrolyte interface influences the battery performance. The interfacial stability between oxide and liquid electrolytes has attracted considerable attention of the electrochemical community in recent years, since oxide SEs are the most widely used inorganic ion-conductive separators for their high chemical stability and acceptable ionic conductivity $\left(\sim 10^{-4} \mathrm{~S} \mathrm{~cm}^{-1}\right) \cdot{ }^{22-23,26-27}$ The studies show that a resistive interphase tends to form at the oxide/liquid electrolyte interface. ${ }^{28}$ More severely, certain oxide SEs with $\mathrm{Ti}^{4+}, \mathrm{Ge}^{4+}$ and $\mathrm{Al}^{3+}$, such as the NASICON-type SEs and even the highly stable garnet SE LLZO, are reactive with the active materials dissolved in liquid electrolytes, leading to corrosion and degradation of the separator. ${ }^{29-}$ ${ }^{30}$ Important efforts are then been made to improve the stability of oxide/liquid electrolyte interface, for examples by redesigning oxide SEs to be compatible with liquid electrolytes, ${ }^{31}$ or by protecting the oxide SE surface with stable polymer coating. ${ }^{32}$ It is worth noting that even the considered highly stable garnet solidelectrolyte LLZO shows poor interfacial stability when it contacts with liquid electrolyte in hybrid batteries. ${ }^{33}$ Comprehensive understanding on the solid/liquid electrolyte interface is required for satisfactorily addressing this interfacial stability issue.

Sulfide SEs have much higher ionic conductivity $\left(10^{-3}-10^{-2} \mathrm{~S} \mathrm{~cm}^{-1}\right)$ than oxide SEs. ${ }^{34-35}$ The combination of sulfide SEs and solvate electrolytes (solvent in salt) has been used to improve the ionic contact of the SEs with the electrode materials in the composite cathode, which is a key issue in all-solid-state batteries. ${ }^{36-37}$ For suppressing the shuttle effect, in-situ formed sulfide SEI (solid electrolyte interphase) layers on Li 
anode has been demonstrated to be effective in several studies, ${ }^{38-41}$ but the studies on sulfide SE separators are seldom reported. As well known, the in-situ formed SEI layers usually suffer from repeated breaking and repairing during the cycling of the batteries. ${ }^{39,}{ }^{42}$ This is detrimental for keeping a high shuttle-suppression ability. Instead, the robust structure of SE separators can completely suppress the shuttle effect, and the reported hybrid batteries using oxide SE separators always exhibit a perfect coulomb ic efficiency of $100 \%$ during long-term operation. ${ }^{22-23,26,31-32}$ Different from the SEI layers, the separators contact not only with anode but also with cathode. Developing sulfide SE separators requires comprehensive knowledge on the chemical and electrochemical stabilities of the sulfide/liquid electrolyte interface under both reduction and oxidation conditions.

Here we systematically study the chemical stability of the interface between $\mathrm{Li}_{2} \mathrm{~S}$ $\mathrm{P}_{2} \mathrm{~S}_{5}$ based glass-ceramic SEs and ether-based liquid electrolyte, as well as their electrochemical stability with both anode and cathode. It is revealed that a stable interface can be achieved with $\beta-\mathrm{Li}_{3} \mathrm{PS}_{4}$ due to the formation of a dense thin layer of solvated $\mathrm{Li}_{3} \mathrm{PS}_{4}$ at the interface, while such a stable interface cannot be formed with the highly ion-conductive $\mathrm{SE} \mathrm{Li}_{7} \mathrm{P}_{3} \mathrm{~S}_{11}$ due to its decomposition by the ether solvent and the resultant porous thick interphase layer. This new understanding on the stability of sulfide/liquid electrolyte interface inspires us to design a $\beta$ - $\mathrm{Li}_{3} \mathrm{PS}_{4}$ coated $\mathrm{Li}_{7} \mathrm{P}_{3} \mathrm{~S}_{11}$ separator with both high ion conduction ability and good interfacial stability, and the advantages have been demonstrated herein by fabricating high-performance hybrid Li$\mathrm{S}$ batteries with this composite separator. 


\section{EXPERIMENTAL SECTION}

\section{Materials}

The used chemical agents were $\mathrm{Li}_{2} \mathrm{~S}\left(99.9 \%\right.$, Alfa Aesar), $\mathrm{P}_{2} \mathrm{~S}_{5}(99 \%$, Qingdao Yurui Ltd.), sublimated sulfur (99.5\%, Alfa Aesar), anhydrous acetonitrile $(\geq 99.5 \%$, Aladdin), anhydrous tetrahydrofuran ( $\geq 99.9 \%$, Sigma-Aldrich). All the chemicals were used as is, without further purification.

\section{Synthesis of $\beta-\mathrm{Li}_{3} \mathrm{PS}_{4} / \mathrm{S}$ by dual -solution-mixing route}

$200.0 \mathrm{mg}$ mixture of $\mathrm{Li} 2 \mathrm{~S}$ and $\mathrm{S}$ (molar ratio 1:5) was stirred in $10 \mathrm{~mL}$ tetrahydrofuran (THF), resulting in a reddish-brown polysulfide $\mathrm{Li}_{2} \mathrm{~S}_{6}$ solution. Meanwhile, $130.3 \mathrm{mg}$ mixture of $\mathrm{Li}_{2} \mathrm{~S}$ and $\mathrm{P}_{2} \mathrm{~S}_{5}$ (molar ratio 1:1) was stirred in $5 \mathrm{~mL}$ acetonitrile $(\mathrm{ACN})$, resulting in a yellow $\mathrm{Li}_{2} \mathrm{~S} \cdot \mathrm{P}_{2} \mathrm{~S}_{5}$ solution. Then the two solutions were mixed to form a homogenous dark brown precursor solution. The preparation of the precursor solution was operated in an argon-filled glovebox $\left(\mathrm{O}_{2}<0.5 \mathrm{ppm}, \mathrm{H}_{2} \mathrm{O}<\right.$ $0.5 \mathrm{ppm})$. The precursor solution was dried at $60{ }^{\circ} \mathrm{C}$ to remove the excess solvent and further heat-treated at $230^{\circ} \mathrm{C}$ under argon for $1 \mathrm{~h}$ to obtain the final products.

\section{Preparation of $\beta-\mathrm{Li}_{3} \mathrm{PS}_{4} / \mathrm{S}$ coated $\mathrm{Li}_{7} \mathrm{P}_{3} \mathrm{~S}_{11}$ separators}

$\mathrm{Li}_{7} \mathrm{P}_{3} \mathrm{~S}_{11}$ was prepared by conventional ball-milling method. $4 \mathrm{~g}$ mixture of $\mathrm{Li}_{2} \mathrm{~S}$ and $\mathrm{P}_{2} \mathrm{~S}_{5}$ (molar ratio 7:3) was put into a $45-\mathrm{mL}$ tungsten carbonide jar with three tungsten carbide grinding balls $(\varphi=10 \mathrm{~mm})$. Then ball milling was conducted at $450 \mathrm{rpm}$ in intermittent manner (5-min run/ 5-min pause) using a planetary ball mill apparatus (Pulverisette 7, Fritsch GmbH, Germany). The effective milling time was $40 \mathrm{~h}$. All the 
operations were conducted in an argon-filled glovebox $\left(\mathrm{O}_{2}<0.5 \mathrm{ppm}, \mathrm{H}_{2} \mathrm{O}<0.5 \mathrm{ppm}\right)$. The resultant $\mathrm{Li}_{2} \mathrm{~S}-\mathrm{P}_{2} \mathrm{~S}_{5}$ glass powder was then cold-pressed into pellets $(\varphi 15 \mathrm{~mm} \times$ $0.85 \mathrm{~mm}$ ) under a pressure of $330 \mathrm{MPa}$. The pellets were sealed in silica glass ampoule under vacuum $\left(10^{-3} \mathrm{~Pa}\right)$ and heat-treated at $260{ }^{\circ} \mathrm{C}$ for $1 \mathrm{~h} . \mathrm{Li}_{7} \mathrm{P}_{3} \mathrm{~S}_{11}$ pellets were obtained. $\beta$ - $\mathrm{Li}_{3} \mathrm{PS}_{4}$ pellets were prepared with the same route, except that the molar ratio of the staring materials $\mathrm{Li}_{2} \mathrm{~S}$ and $\mathrm{P}_{2} \mathrm{~S}_{5}$ was 7.5:2.5.

Dip-coating method was used to form a thin layer of $\beta-\mathrm{Li}_{3} \mathrm{PS}_{4} / \mathrm{S}$ around the $\mathrm{Li}_{7} \mathrm{P}_{3} \mathrm{~S}_{11}$ pellets as follows: The pellets were firstly immersed into the precursor solution prepared by the dual-solution-mixing route as mentioned above. Then the pellets were slowly pulled up to form a thin layer of solution on the surface and naturally dried at room temperature in an argon-filled glovebox $\left(\mathrm{O}_{2}<0.5 \mathrm{ppm}, \mathrm{H}_{2} \mathrm{O}<0.5 \mathrm{ppm}\right)$. The dipcoating repeated 5 times. Finally, the pellets were heat-treated at $230{ }^{\circ} \mathrm{C}$ under argon for $1 \mathrm{~h}$ to complete the coating.

\section{Materials characterization}

X-ray diffraction (D8 Advance, Bruker AXS GmbH, Germany) were used to monitor the phase evolution during the sample preparation. Raman spectra were recorded by a Raman spectrometer (inVia, Renishaw Inc., UK) with a $532 \mathrm{~nm}$ diode-pumped solidstate laser as the excitation source. To protect the samples from exposure to humidity, they were mounted in the sample holder and sealed by polyimide cover films in the glovebox prior to XRD and Raman characterization. The morphology of the samples was recorded by a field-emission scanning electron microscope (SU8010, Hitachi Inc., 
Japan). The scanning electron microscope was equipped with an energy dispersive $\mathrm{X}$ ray microanalyzer, which characterizes the composition of the samples. X-ray photoelectron spectroscopy (XPS) was measured using Thermo Scientific ESCALAB 250Xi with $\mathrm{Al} \mathrm{K \alpha} \alpha$-radiation. Vacuum transfer box was used to transfer the samples from glovebox to the characterization equipment.

The ionic conductivity was measured by an $\mathrm{AC}$ impedance method in an argon filled glovebox, using a frequency response analyzer (Solartron 1260A, Solartron Analytical Inc., UK). The conductivity of the samples was then determined from the impedance spectra data. For powder samples, they were sandwiched between two layers of acetylene black powder and cold-pressed into pellets $(15 \mathrm{~mm}$ diameter and $\sim 1 \mathrm{~mm}$ thickness) with $330 \mathrm{MPa}$ pressure. For pre-sintered solid electrolyte separators, they were sandwiched between two stainless-steel disks and the interface between them was wetted by $15 \mu \mathrm{L}$ commercial liquid electrolyte (1 M LiTFSI DME/DOL (50-50 vol\%)$1 \% \mathrm{LiNO}_{3}$, DoDoChem Inc.) to improve the electrical contact.

\section{Electrochemical measurements}

Hybrid Li-S batteries were assembled in an argon-filled glovebox $\left(\mathrm{O}_{2}<0.5 \mathrm{ppm}\right.$, $\mathrm{H}_{2} \mathrm{O}<0.5$ ppm) into CR2032-type coin cells with a structure of -)SUS/Li/ liquid electrolyte/solid electrolyte/liquid electrolyte/S-C/SUS(+. The cathode was obtained by ultrasonic spraying the ethanol suspension of S-C composite, LA133 binder and conductive acetylene black (8:1:1, wt $\%)$ on carbon paper, where the S-C composite was prepared in advance by heating the ground mixture of ketjen black and $\mathrm{S}$ at $155^{\circ} \mathrm{C}$ for 
$12 \mathrm{~h}$ under vacuum with $60 \mathrm{wt} \%$ sulfur loading in the composite. The sulfur load in the cathode was $0.85 \mathrm{mg} \mathrm{cm}$. The cathode and anode sides of the SE separator were wetted by $40 \mu \mathrm{L}$ and $10 \mu \mathrm{L}$ liquid electrolyte (1 M LiTFSI DME/DOL (50-50 vol\%)$1 \% \mathrm{LiNO}_{3}$ ), respectively. The batteries were stored in the glovebox one night before test. The galvanostatic charge-discharge test was carried out on a battery tester (CT2001, Land Ins., Wuhan, China) in a voltage range of 1.5-2.8 V. The impedance spectra of the batteries with a frequency range of $10^{-2}-10^{5} \mathrm{~Hz}$ were recorded by an electrochemical workstation (CHI660E, CH Instruments Ins., Shanghai, China).

Cyclic voltammetry of -$)$ Li/solid electrolyte/liquid electrolyte/Stainless steel(+ halfcells was measured by the CHI660E electrochemical workstation to study the electrochemical stability of different solid-electrolyte separators in solid-liquid-hybrid environment. $10 \mu \mathrm{L}$ liquid electrolyte (1 M LiTFSI DME/DOL (50-50 vol\%)-1\% $\mathrm{LiNO}_{3}$ ) was dropped between the SE pellet and the stainless-steel electrode to create a solid-liquid electrolyte interface which exists within the hybrid batteries. Symmetric cells with a structure of Li/liquid electrolyte/solid electrolyte/liquid electrolyte/Li were assembled in Swagelok battery moulds. $10 \mu \mathrm{L}$ liquid electrolyte was dropped between the SE pellet and the Li electrode. Their plating/stripping profiles were measured by the CT2001 battery tester. All the cells were stored for about $12 \mathrm{~h}$ before the test to complete the formation of the interphase layer at the sulfide/liquid electrolyte interface.

\section{RESULTS AND DISCUSSION}

\section{Chemical stability with ether-based solvent}


Two typical $\mathrm{Li}_{2} \mathrm{~S}-\mathrm{P}_{2} \mathrm{~S}_{5}$ based glass-ceramic $\mathrm{SEs}, \mathrm{Li}_{7} \mathrm{P}_{3} \mathrm{~S}_{11}$ and $\beta-\mathrm{Li}_{3} \mathrm{PS}_{4}$ are studied here. $\mathrm{Li}_{7} \mathrm{P}_{3} \mathrm{~S}_{11}$ is a well-known highly ion-conductive $\mathrm{SE}$ with an extremely high ionic conductivity of $1.7 \times 10^{-2} \mathrm{~S} \mathrm{~cm}^{-1} .{ }^{34} \beta-\mathrm{Li}_{3} \mathrm{PS}_{4}$, or denoted as thio-LISICON III analogue by Tatsumisago, has lower ionic conductivity of $2.8 \times 10^{-4} \mathrm{~S} \mathrm{~cm}^{-1},{ }^{43}$ but is believed to have better chemical stability. ${ }^{44}$ Both of them are metastable at room temperature, and should be prepared by crystallization of the $\mathrm{Li}_{2} \mathrm{~S}-\mathrm{P}_{2} \mathrm{~S}_{5}$ base glasses.

The chemical stability of the two $\mathrm{Li}_{2} \mathrm{~S}-\mathrm{P}_{2} \mathrm{~S}_{5}$ based $\mathrm{SEs}$ with ether solvent was firstly checked by immersion experiment. A mixture of 1,3-dioxolane (DOL) and dimethoxyethane (DME) with volumetric ratio of 1:1 was used as the solvent. It is a standard solvent for the liquid electrolyte of Li-S batteries. After $48 \mathrm{~h}$ immersion in the solvent and vacuum-drying at $80{ }^{\circ} \mathrm{C}$, the structure change of the $\mathrm{SE}$ powders was examined by XRD and Raman, as shown in Figure 1a and 1b. XRD shows that the immersion products of both SEs contain a crystalline phase assigned to DME-solvated $\mathrm{Li}_{3} \mathrm{PS}_{4} .{ }^{45-46}$ Two major peaks are observed in the Raman spectra of the immersed powders. One peak at $421 \mathrm{~cm}^{-1}$ is assigned to the ether-solvated $\mathrm{PS}_{4}{ }^{3-}$ anion, which is a major structural unit of $\mathrm{Li}_{3} \mathrm{PS}_{4}{ }^{46}$ The other peak at $388 \mathrm{~cm}^{-1}$ is assigned to the ethersolvated vertex-shared $\mathrm{PS}_{4}$ tetrahedral anions, ${ }^{46}$ which is not a typical structural unit of $\mathrm{Li}_{3} \mathrm{PS}_{4}$. An intense $388-\mathrm{cm}^{-1}$ peak appears in the immersed $\mathrm{Li}_{7} \mathrm{P}_{3} \mathrm{~S}_{11}$ indicating that besides the crystalline DME-solvated $\mathrm{Li}_{3} \mathrm{PS}_{4}$, an amorphous phase containing vertexshared $\mathrm{PS}_{4}$ tetrahedral anions exists. Recent studies on liquid phase synthesis of $\mathrm{Li}_{7} \mathrm{P}_{3} \mathrm{~S}_{11}$ in acetonitrile reveal that the starting materials $\mathrm{Li}_{2} \mathrm{~S}$ and $\mathrm{P}_{2} \mathrm{~S}_{5}$ react into crystalline $\mathrm{Li}_{3} \mathrm{PS}_{4} \cdot \mathrm{ACN}$ and amorphous " $\mathrm{Li}_{2} \mathrm{~S} \cdot \mathrm{P}_{2} \mathrm{~S}_{5}$ " phases in the solvent, ${ }^{47}$ where the 
" $\mathrm{Li}_{2} \mathrm{~S} \cdot \mathrm{P}_{2} \mathrm{~S}_{5}$ " phase is constituted by vertex-shared $\mathrm{PS}_{4}$ tetrahedral anions whose major Raman signal is at $383 \mathrm{~cm}^{-1} \cdot{ }^{48}$ It is therefore proposed to assign this amorphous immersion product of $\mathrm{Li}_{7} \mathrm{P}_{3} \mathrm{~S}_{11}$ to an ether-solvated " $\mathrm{Li} 2 \mathrm{~S} \cdot \mathrm{P}_{2} \mathrm{~S}_{5}$ " phase. According to the phase structure analysis, we conclude that $\beta-\mathrm{Li}_{3} \mathrm{PS}_{4}$ is solvated while $\mathrm{Li}_{7} \mathrm{P}_{3} \mathrm{~S}_{11}$ is decomposed by the solvent.

The $80{ }^{\circ} \mathrm{C}$-dried immersed products exhibit dramatically reduced electrical conductivity, that is, $1.8 \times 10^{-8} \mathrm{~S} \mathrm{~cm}^{-1}$ for $\mathrm{Li}_{7} \mathrm{P}_{3} \mathrm{~S}_{11}$ and $1.4 \times 10^{-10} \mathrm{~S} \mathrm{~cm}^{-1}$ for $\beta$-Li3 $\mathrm{PS}_{4}$ (Figure S4). Since the electrical conductivity of the sulfide solid electrolyte is mainly provided by the ion conduction, the dramatical decrease of the electrical conductivity of the immersed products indicates that the reaction of the $\mathrm{Li}_{2} \mathrm{~S}-\mathrm{P}_{2} \mathrm{~S}_{5}$ based SEs with the ether solvent is detrimental for ion conduction. The results of the immersion experiment coincide with the general knowledge that sulfide SEs exhibit poor chemical stability since the SE powders completely react with the solvent within only $48 \mathrm{~h}$ immersion. In fact, even oxide and oxynitride SEs tend to react with polar solvents because they are rich in $\mathrm{Li}^{+}$ions which act as strong Lewis acid centers and are reactive due to the basicity of many polar solvents. ${ }^{28,49}$

A highly promising result is obtained during the in-situ monitoring of the interfacial resistance between the sulfide SE pellets and the liquid electrolyte. For this test, the pre-sintered SE pellet (diameter of $1.5 \mathrm{~cm}$ ) was sandwiched between two stainless-ste e1 (SS) disk electrodes and the interface between them was wetted by $15 \mu \mathrm{L}$ commercial liquid electrolyte (1 M LiTFSI DME/DOL (50-50 vol\%)-1\% $\mathrm{LiNO}_{3}$ ). The temporal 
evolution of the interfacial resistance is obtained from the impedance spectra (F igure S5). As shown in Figure 1c, the interfacial resistance of both samples quickly increases in the first $6 \mathrm{~h}$, reflecting the formation of solvated interphase layers. Considering the formation of interphase layers at the oxide/liquid electrolyte interface takes tens of hours, ${ }^{28}$ the rapid formation of such layers at the sulfide/liquid electrolyte interface coincides with the weak chemical stability of sulfide SEs. After the initial formation stage, the evolution of the interfacial resistance for the $\mathrm{Li}_{7} \mathrm{P}_{3} \mathrm{~S}_{11}$ pellet and the $\beta$-Li3 $\mathrm{PS}_{4}$ pellet shows different trends. The interfacial resistance of the $\mathrm{Li}_{7} \mathrm{P}_{3} \mathrm{~S}_{11}$ pellet continuously increases to more than $400 \Omega$ in the following $200 \mathrm{~h}$. Interestingly, for the $\beta$-Lis $\mathrm{PS}_{4}$ pellet, the interfacial resistance keeps at a low value of about $50 \Omega$ during the 200-hour test, showing excellent stability. After the 200-hour test, the surface of the $\mathrm{Li}_{7} \mathrm{P}_{3} \mathrm{~S}_{11}$ pellet becomes rough while that of the $\beta$-Lis $\mathrm{PS}_{4}$ pellet is still smooth (insert of Figure 1d-e). Detailed morphology change was characterized by SEM. The top-view image of the $\beta$ - $\mathrm{Li}_{3} \mathrm{PS}_{4}$ pellet shows a porous surface (Figure 1d). This porous structure belongs to an interphase layer with a thickness of about $2.5 \mu \mathrm{m}$ (Figure 1f). EDS linescan shows that the layer is rich of $\mathrm{C}$ and $\mathrm{O}$, confirming that it is an ether-solvated interphase layer. For the $\beta$ - $\mathrm{Li}_{3} \mathrm{PS}_{4}$ pellet, a dense thin interphase layer packed by nanocrystals can be observed, whose thickness is only $0.4 \mu \mathrm{m}$ (Figure $1 \mathrm{e}$ and $1 \mathrm{~g}$ ). Additionally, some large crystals with a size of several micrometers scatter on the surface. EDS mapping (Figure S7) reveals that these large crystals have the same composition with the nano-crystals which form the dense interphase layer. We propose 
that they are all attributed to DME-solvated $\mathrm{Li}_{3} \mathrm{PS}_{4}$, the only solvated crystalline phase detected by XRD.

Whether a dense solvated interphase layer forms at the solid/liquid electrolyte interface depends on the physicochemical properties of the solvated products. Solvated $\mathrm{Li}_{3} \mathrm{PS}_{4}$ has been widely observed insoluble in various organic polar solvents. ${ }^{50-52}$ Due to the insolubility of the solvated $\mathrm{Li}_{3} \mathrm{PS}_{4}$, it can form a dense layer at the interface between $\beta$ - $\mathrm{Li}_{3} \mathrm{PS}_{4}$ and the solvent, and can prevent further solvation of $\beta$ - $\mathrm{Li}_{3} \mathrm{PS}_{4}$. Differently, the solvated " $\mathrm{Li} 2 \mathrm{~S} \cdot \mathrm{P}_{2} \mathrm{~S}_{5}$ " phase is soluble or partially soluble in polar solvents due to the more scattered charge density of its vertex-shared $\mathrm{PS}_{4}$ tetrahedral anions and therefore the weaker ionic bond with $\mathrm{Li}^{+}$ions. ${ }^{48}$ As discussed above, $\mathrm{Li}_{7} \mathrm{P}_{3} \mathrm{~S}_{11}$ is decomposed by the ether solvent into solvated $\mathrm{Li}_{3} \mathrm{PS}_{4}$ and " $\mathrm{Li} 2 \mathrm{~S} \cdot \mathrm{P}_{2} \mathrm{~S}_{5}$ ". The gradual dissolution of " $\mathrm{Li} 2 \mathrm{~S} \cdot \mathrm{P}_{2} \mathrm{~S}_{5}$ " results in pinholes in the interphase layer which provide pathways for continuous reaction between $\mathrm{Li}_{7} \mathrm{P}_{3} \mathrm{~S}_{11}$ and the solvent.

It is worth noting that the $\mathrm{Li}_{2} \mathrm{~S}-\mathrm{P}_{2} \mathrm{~S}_{5}$ glass-ceramic powder is reactive with the etherbased liquid electrolyte so this hybrid electrolyte is not suitable for composite cathodes of solid-state batteries. Instead, a solvent-in-salt electrolyte (salt/solvent=1/1) is required to stabilize the solid/liquid electrolyte interface. ${ }^{37}$ Differently, as the separator of a battery, the $\mathrm{Li}_{2} \mathrm{~S}-\mathrm{P}_{2} \mathrm{~S}_{5}$ glass-ceramic pellet can be stable with the ether-based liquid electrolyte due to the formation of the solvated interphase layer on the surface. This is like the stability of aluminum in the air, that is, aluminum powder is quite reactive while bulk aluminum is stable because of the dense $\mathrm{Al}_{2} \mathrm{O}_{3}$ passivation layer. Here, the dense 
interphase layer can be formed on $\beta-\mathrm{Li}_{3} \mathrm{PS}_{4}$ but not on $\mathrm{Li}_{7} \mathrm{P}_{3} \mathrm{~S}_{11}$. In summary, the $\beta$ $\mathrm{Li}_{3} \mathrm{PS}_{4} /$ ether interface can be stabilized due to the formation of a dense thin solvated interphase layer.
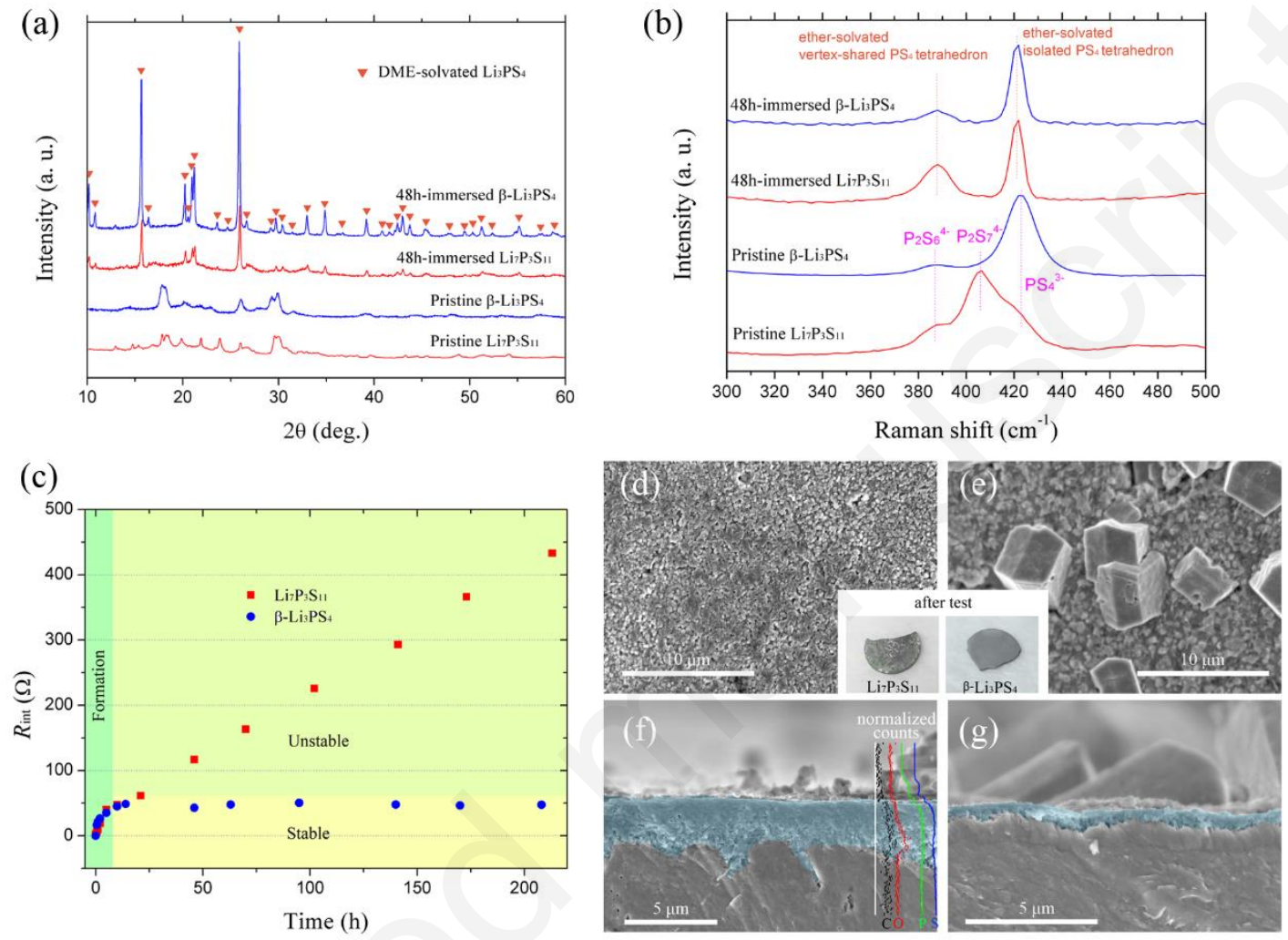

Figure 1. Chemical stability of the $\mathrm{Li}_{2} \mathrm{~S}-\mathrm{P}_{2} \mathrm{~S}_{5}$ based glass-ceramic SEs with ether solvent.

(a) XRD pattens and (b) Raman spectra of the $\mathrm{Li}_{7} \mathrm{P}_{3} \mathrm{~S}_{11}$ and $\beta$ - $\mathrm{Li}_{3} \mathrm{PS}_{4}$ powders before and after 48 $\mathrm{h}$ immersion in a mixed solvent DOL/DME (50-50 vol\%). (c) Evolution of the interfacial resistance of the sulfide/liquid electrolyte interface in the SS/liquid electrolyte/SE/liquid electrolyte/SS cells. Top-view and cross-sectional SEM images of $(d, f)$ the $\mathrm{Li}_{7} \mathrm{P}_{3} \mathrm{~S}_{11}$ pellet and (e, g) the $\beta$-Li3 $\mathrm{PS}_{4}$ pellet after $200 \mathrm{~h}$ test in the $\mathrm{SS} /$ liquid electrolyte/SE/liquid electrolyte/SS cells.

The insert shows their photos. EDS line-scan results of the elements C, O, P and S are overlapped on the cross-sectional SEM image in (f). 


\section{Electrochemical stability of the sulfide/liquid electrolyte interface}

The plating/stripping cycling of symmetric cells with lithium electrode (at constant current of $0.23 \mathrm{~mA} \mathrm{~cm}$ ) was conducted to characterize the interfacial stability under reduction condition. To create a sulfide/liquid electrolyte interface, $10 \mu \mathrm{L}$ liquid electrolyte (1 M LiTFSI DME/DOL (50-50 vol\%)-1\% $\mathrm{LiNO}_{3}$ ) was dropped between the SE pellet and the lithium electrodes. The structure of the symmetric cells was Li/liquid electrolyte/solid electrolyte/liquid electrolyte/Li. The cells were stored for about $12 \mathrm{~h}$ before the test to complete the formation of the interphase layer at the sulfide/liquid electrolyte interface. As shown by the plating/stripping profiles in Figure $2 \mathrm{a}$, both the symmetric cells with $\mathrm{Li}_{7} \mathrm{P}_{3} \mathrm{~S}_{11}$ and $\beta$ - $\mathrm{Li}_{3} \mathrm{PS}_{4}$ operate at an almost unchanged voltage for more than $200 \mathrm{~h}$, reflecting that the $\mathrm{Li}_{2} \mathrm{~S}_{-} \mathrm{P}_{2} \mathrm{~S}_{5}$ glass-ceramic and the $\mathrm{Li}$ anode are electrochemically compatible with the existence of the liquid electrolyte. For longer testing, short-circuit accidentally occurs. The short-circuit is caused by the lithium penetration in the solid electrolytes. Recent studies reveal that the poor contact between solid electrolytes and the lithium anode is a principal reason for the lithium

penetration. ${ }^{53}$ Additionally, defects such as grain boundaries, pores and cracks facilita te the growth of lithium dendrites. ${ }^{54}$ The lithium penetration issue has been demonstrated to be ameliorated by engineering interlays between lithium and solid electrolytes, ${ }^{55-57}$ and by improving the density of the solid electrolyte. ${ }^{58}$ In our case, the coexistence of liquid and solid electrolytes as well as the in-situ formed solvated interphase layer even complicate the properties of the interface with the lithium anode, make it complex to 
understand this lithium penetration phenomenon. Studies on lithium penetration under hybrid condition is being undertaken. Its discussion is beyond the scope of this article.

The stability is also illustrated by the little change of the impedance spectra of the cells after $100 \mathrm{~h}$ operation (Figure $2 \mathrm{~b}-\mathrm{d}$ ). The symmetric cell with $\beta$-Li3 $\mathrm{PS}_{4}$ has smaller interfacial resistance, but larger bulk resistance due to its lower ionic conductivity. Consequently, the overpotential of this cell is larger than the one with $\mathrm{Li}_{7} \mathrm{P}_{3} \mathrm{~S}_{11}$. It is worth noting that the interfacial resistance of the $\mathrm{Li}_{7} \mathrm{P}_{3} \mathrm{~S}_{11} /$ liquid electrolyte interface reduces to a stable value of $34 \Omega$ under reduction condition, much smaller than that shown in Figure 1c. It indicates that the interfacial chemistry changes due to the existence of lithium. Liang et al. have reported that an SEI layer mainly composed of $\mathrm{Li}_{3} \mathrm{PS}_{4}$ can be in-situ formed by the reaction between lithium and $\mathrm{P}_{2} \mathrm{~S}_{5}$ additive, ${ }^{38}$ showing that Li has the ability to break the P-S-P bridged structure in $\mathrm{P}_{2} \mathrm{~S}_{5}$ to form $\mathrm{P}$ $\mathrm{S}^{-}$structure in $\mathrm{Li}_{3} \mathrm{PS}_{4}$. It is therefore reasonable to assume that the decomposition product " $\mathrm{Li} 2 \mathrm{~S} \cdot \mathrm{P}_{2} \mathrm{~S}_{5}$ " with the same P-S-P bridge structure can also be converted into solvated $\mathrm{Li}_{3} \mathrm{PS}_{4}$ by $\mathrm{Li}$, therefore leading to improved interfacial stability. This assumption is further confirmed by the XPS $S_{2 p}$ spectra of the lithium anodes of the symmetric cells after cycling (Figure S8). A strong $\mathrm{S}_{2 \mathrm{p} 3 / 2}$ peak at $161.4 \mathrm{eV}$, which is assigned to $\mathrm{PS}_{4}{ }^{3-},{ }^{40}$ can be detected in these spectra, indicating that an in-situ formed SEI layer containing $\mathrm{Li}_{3} \mathrm{PS}_{4}$ exists on the lithium anode. Moreover, The $\mathrm{PS}_{4}{ }^{3-}$ signal is much more intense for the sample with $\mathrm{Li}_{7} \mathrm{P}_{3} \mathrm{~S}_{11}$ than with $\beta$-Lis $\mathrm{PS}_{4}$. This is accordance with the assumption that the partially soluble decomposition product " $\mathrm{Li} 2 \mathrm{~S} \cdot \mathrm{P}_{2} \mathrm{~S}_{5}$ " from $\mathrm{Li}_{7} \mathrm{P}_{3} \mathrm{~S}_{11}$ facilitates the reaction with $\mathrm{Li}$ to form the $\mathrm{Li}_{3} \mathrm{PS}_{4}$-containing $\mathrm{SEI}$ layer. This 
SEI layer may slightly increase the interfacial resistance, but benefits the interfacial stability, which result in a more stable interfacial resistance in the symmetric cell with $\mathrm{Li}_{7} \mathrm{P}_{3} \mathrm{~S}_{11}$ as shown in Figure $2 \mathrm{~d}$.

(a)

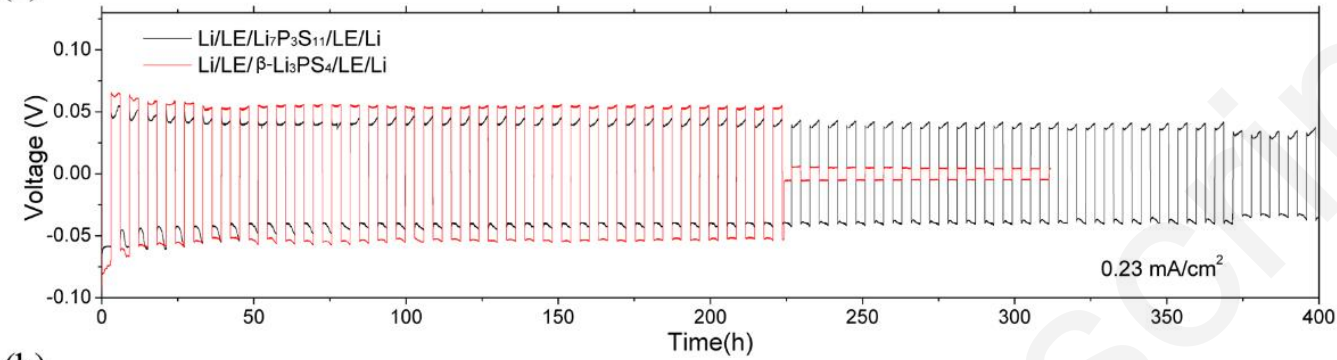

(b)

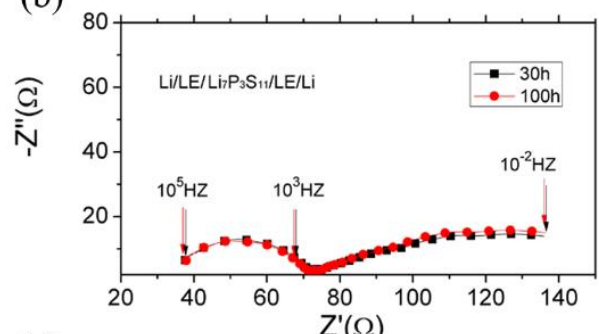

(c)
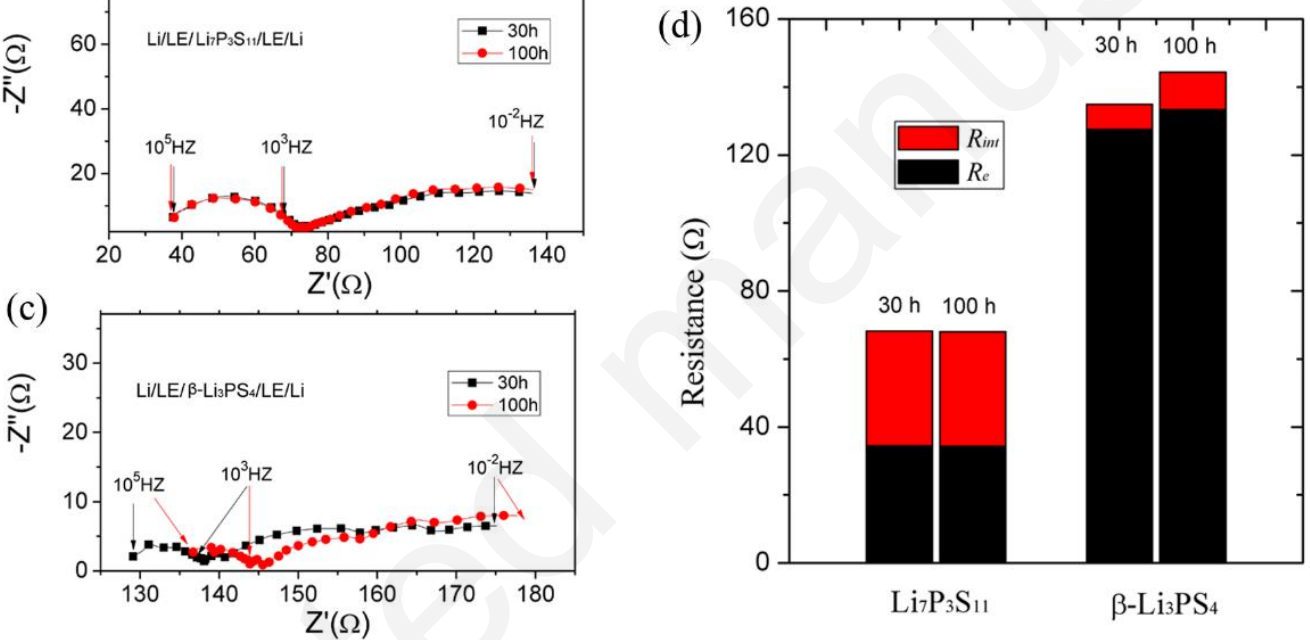

$\mathrm{Li}_{7} \mathrm{P}_{3} \mathrm{~S}_{11} \quad \beta-\mathrm{Li}_{3} \mathrm{PS}_{4}$


Figure 2. Stability of the sulfide/liquid electrolyte interface with the lithium electrode. (a)

Plating/stripping profiles and (b-c) impedance spectra recorded after $30 \mathrm{~h}$ and $100 \mathrm{~h}$ cycling of $\mathrm{Li} /$ liquid electrolyte/solid electrolyte/liquid electrolyte/Li symmetric cells where solid electrolytes are $\mathrm{Li}_{7} \mathrm{P}_{3} \mathrm{~S}_{11}$ and $\beta-\mathrm{Li}_{3} \mathrm{PS}_{4}$, respectively. The lines are provided to guide the eye. (d) Electrolyte resistance $R_{e}$ and interfacial resistance $R_{\text {int }}$ deduced from the impedance spectra. SEM images of 
the lithium electrode surfaces (e) before and (f-g) after the plating/stripping cycling in the symmetric cells.

Figure 2e-g shows the morphology of the lithium electrode before and after the plating/stripping test. A smooth surface of lithium can be observed before cycling. After the test, the surficial roughness increases due to the plating/stripping cycling of $\mathrm{Li}$, but no $\mathrm{Li}$ dendrites are evidently observed. In summary, both $\mathrm{Li}_{7} \mathrm{P}_{3} \mathrm{~S}_{11}$ and $\beta$ - $\mathrm{Li}_{3} \mathrm{PS}_{4}$ can form stable interface with the ether-based liquid electrolyte under reduction condition, showing their good compatibility in contact with lithium metal.

While the interfacial stability between SEs and Li metal has attracted wide attention, here we emphasize that the oxidization condition at the cathode side of batteries has decisive influence on the stability of the $\mathrm{Li}_{2} \mathrm{~S}-\mathrm{P}_{2} \mathrm{~S}_{5}$ based glass-ceramic SEs/ether solvent interface. To demonstrate this, the cyclic voltammetry (CV) of -) Li/solid electrolyte/liquid electrolyte/stainless-steel (+ half-cells was conducted (Figure 3). 10 $\mu \mathrm{L}$ liquid electrolyte (1 M LiTFSI DME/DOL (50-50 vol\%)-1\% $\mathrm{LiNO}_{3}$ ) was dropped between the SE pellet and the stainless-steel electrode to create a solid/liquid electrolyte interface. The influence of the liquid electrolyte on the electrochemical stability of the $\mathrm{Li}_{7} \mathrm{P}_{3} \mathrm{~S}_{11}$ is firstly studied by comparing the CV of two half-cells with and without the liquid electrolyte in Figure 3b. It can be seen that without liquid electrolyte the solid state half-cell exhibits negligible redox current, showing excellent electrochemical stability. Differently, in the hybrid cell strong redox current is observed, revealing the poor electrochemical stability of $\mathrm{Li}_{7} \mathrm{P}_{3} \mathrm{~S}_{11}$ under solid-liquid hybrid environment. It is 
well known that $\mathrm{Li}_{7} \mathrm{P}_{3} \mathrm{~S}_{11}$ is thermodynamically unstable whose electrochemical window is quite narrow. ${ }^{59}$ Fortunately, its decomposition products form SEI layers in all-solid-state batteries, which prevent further decomposition of $\mathrm{Li}_{7} \mathrm{P}_{3} \mathrm{~S}_{11}$. However, such stable SEI layers cannot be formed in hybrid batteries due to the etching of organic solvent, so the intrinsic poor electrochemical stability of $\mathrm{Li}_{7} \mathrm{P}_{3} \mathrm{~S}_{11}$ is manifested.

(a)

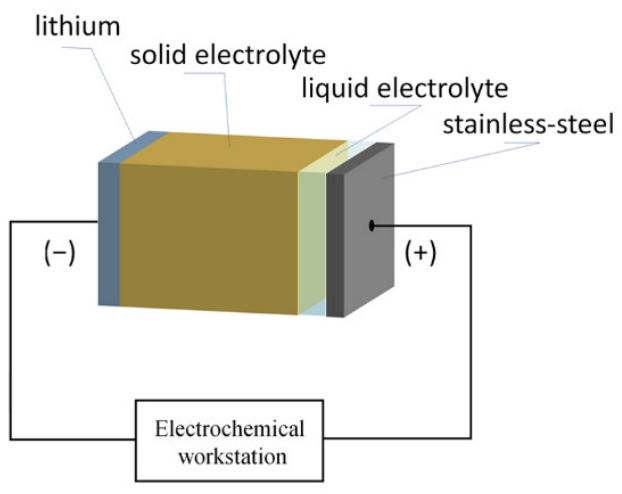

(c) (b)

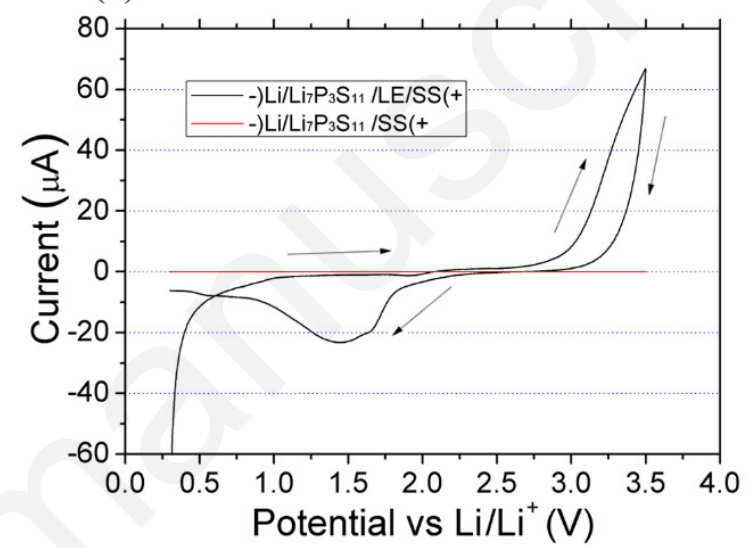

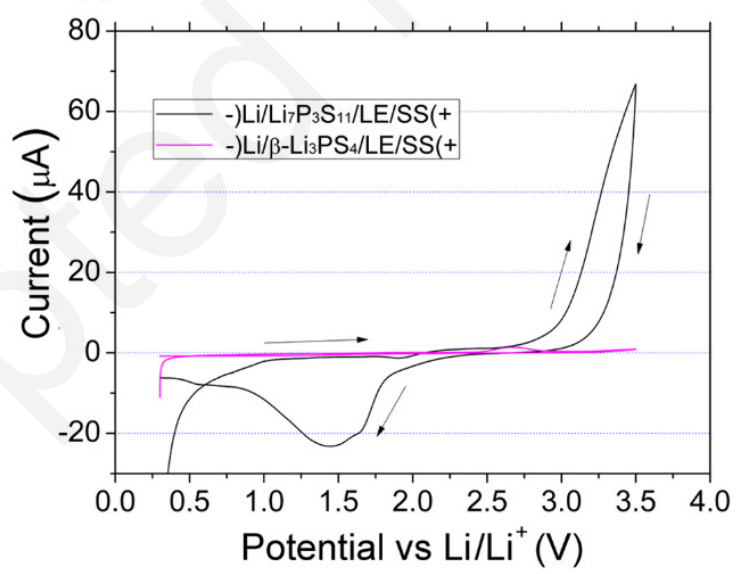

Figure 3. Stability of the sulfide/liquid electrolyte interface under oxidization condition. (a)

Scheme of the cyclic voltammetry measurement to study the electrochemical stability of different solid electrolytes in solid-liquid-hybrid environment. (b) Cyclic voltammetry of

$-) \mathrm{Li} / \mathrm{Li}_{7} \mathrm{P}_{3} \mathrm{~S}_{11} /$ liquid electrolyte/SS( + and -$) \mathrm{Li} / \mathrm{Li}_{7} \mathrm{P}_{3} \mathrm{~S}_{11} / \mathrm{SS}(+$ half-cells showing the poor 
electrochemical stability of $\mathrm{Li}_{7} \mathrm{P}_{3} \mathrm{~S}_{11}$ in hybrid environment. (c) Cyclic voltammetry of -)Li/solid electrolyte/liquid electrolyte/SS(+ half-cells revealing the excellent electrochemical stability of $\beta$ $\mathrm{Li}_{3} \mathrm{PS}_{4}$ with liquid electrolyte. Scanning rate is $0.1 \mathrm{mV} \mathrm{s}^{-1}$.

During the anodic sweep, $\mathrm{Li}_{7} \mathrm{P}_{3} \mathrm{~S}_{11}$ shows an onset of anodic current at $2.5 \mathrm{~V}$, which monotonically increases to $67 \mu \mathrm{A}$ at $3.5 \mathrm{~V}$. As for $\beta$ - $\mathrm{Li}_{3} \mathrm{PS}_{4}$, an anodic current peak starts at $2.4 \mathrm{~V}$, and after the peak, the current monotonically increases to $0.9 \mu \mathrm{A}$ at 3.5 $\mathrm{V}$ (Figure 3c). According to previous theoretical and experimental studies, the anodic current is attributed to the delithiation process of lithium thiophosphates. ${ }^{59-60}$ The much lower anodic current of $\beta$ - $\mathrm{Li}_{3} \mathrm{PS}_{4}$ than that of $\mathrm{Li}_{7} \mathrm{P}_{3} \mathrm{~S}_{11}$ indicates that the former is electrochemically more stable with the liquid electrolyte under an oxidization condition.

\section{Interfacial engineering with sulfide solid electrolytes}

It has been demonstrated that $\beta$ - $\mathrm{Li}_{3} \mathrm{PS}_{4}$ can form chemically/electrochemically stable interface with ether-based electrolyte, while more ion-conductive $\mathrm{Li}_{7} \mathrm{P}_{3} \mathrm{~S}_{11}$ cannot. This discovery on the stability of sulfide/liquid electrolyte interfaces can inspire novel designs of SE separators for high-performance rechargeable batteries. As an example, we propose here that coating $\mathrm{Li}_{7} \mathrm{P}_{3} \mathrm{~S}_{11}$ separators with a submicrometric layer of $\beta$ $\mathrm{Li}_{3} \mathrm{PS}_{4}$ is expected to be an effective strategy to develop highly ion-conductive separator with good interfacial stability for hybrid Li-S batteries (Figure 4a). Enhanced cycling performance can be achieved by the combination of three electrolytes, where $\mathrm{Li}_{7} \mathrm{P}_{3} \mathrm{~S}_{11}$ inhibits the polysulfide shutting and provides fast $\mathrm{Li}^{+}$transportation, ether- 
based liquid electrolyte ensures excellent redox kinetics in electrodes and thin $\beta$ - $\mathrm{Li}_{3} \mathrm{PS}_{4}$ coating stabilizes the solid/liquid electrolyte interface.
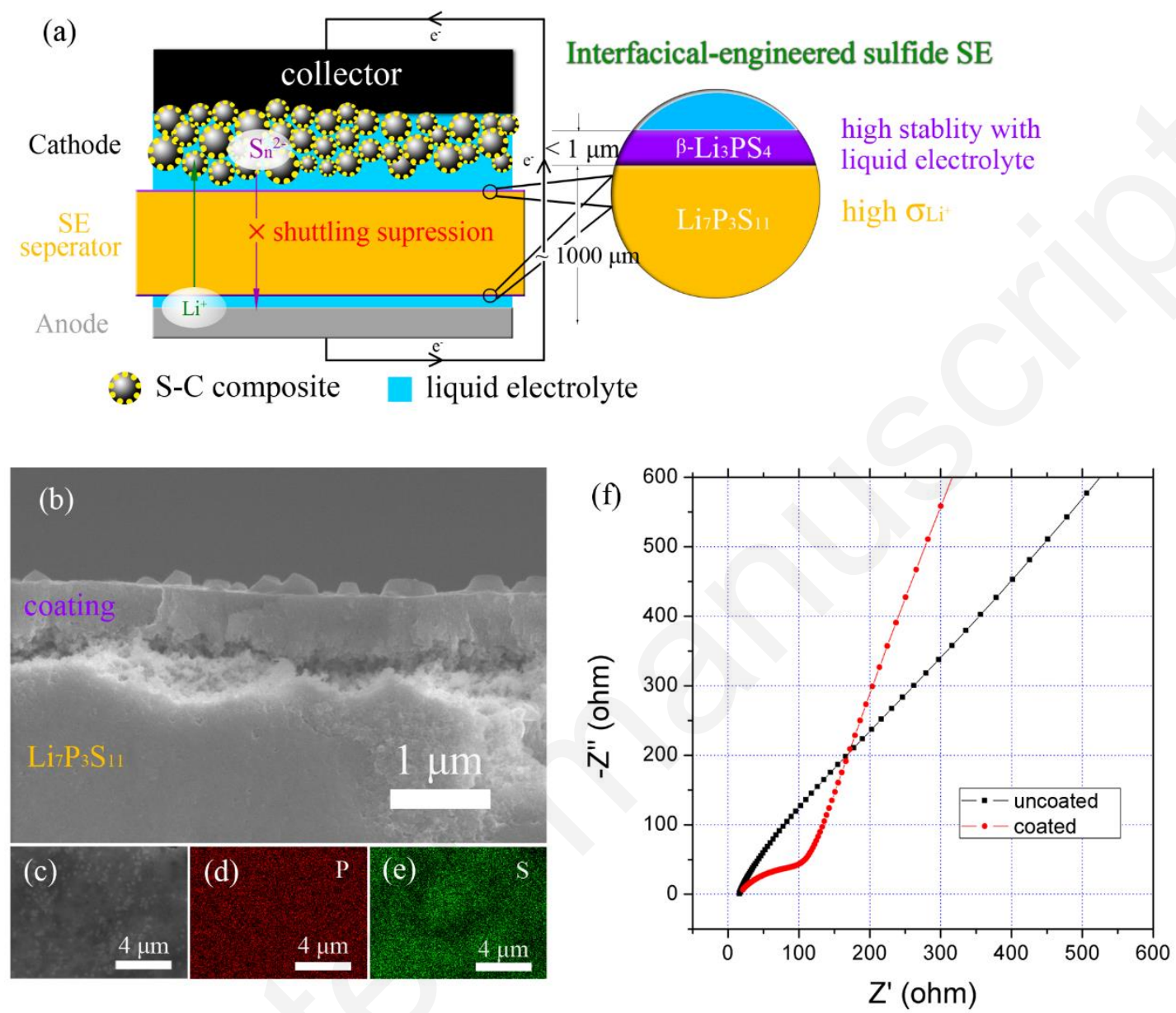

Figure 4. Interfacial-engineered sulfide solid electrolyte for hybrid Li-S batteries. (a)

Strategy for developing sulfide SE separators in hybrid Li-S batteries by coating highly ionconductive $\mathrm{Li}_{7} \mathrm{P}_{3} \mathrm{~S}_{11}$ with a thin layer of $\beta-\mathrm{Li}_{3} \mathrm{PS}_{4}$ that is more stable with the liquid electrolyte. (b) SEM cross-section image of $\beta$ - $\mathrm{Li}_{3} \mathrm{PS}_{4} / \mathrm{S}$ coating on a $\mathrm{Li}_{7} \mathrm{P}_{3} \mathrm{~S}_{11}$ separator. (c) Top-view SEM image of $\beta-\mathrm{Li}_{3} \mathrm{PS}_{4} / \mathrm{S}$ coating and EDS mapping of phosphor (d) and sulfur (e). (f) Impedance spectra of coated and uncoated $\mathrm{Li}_{7} \mathrm{P}_{3} \mathrm{~S}_{11}$ separators whose dimension is $\varphi 15 \mathrm{~mm} \times 1 \mathrm{~mm}$.

Conventional synthesis techniques of $\mathrm{Li}_{2} \mathrm{~S}-\mathrm{P}_{2} \mathrm{~S}_{5}$ based $\mathrm{SEs}$, such as meltingquenching, ${ }^{61}$ ball milling ${ }^{62}$ and suspension synthesis, ${ }^{63}$ always result in granular 
products, which cannot be used for preparing thin dense coating of $\beta-\mathrm{Li}_{3} \mathrm{PS}_{4}$. Here we developed, a dual-solution-mixing route for preparing $\beta$ - $\mathrm{Li}_{3} \mathrm{PS}_{4}$-based dense coating (details in Supplementary Information). With this technique, an ion-conductive composite of $\beta$ - $\mathrm{Li}_{3} \mathrm{PS}_{4}$ and sulfur (Figure S9) can be prepared by using a homogeno us precursor solution.

By using dip-coating method with the homogenous precursor solution, a dense film of $\beta-\mathrm{Li}_{3} \mathrm{PS}_{4} / \mathrm{S}$ with thickness of about $400-600 \mathrm{~nm}$ can be formed on a $\mathrm{Li}_{7} \mathrm{P}_{3} \mathrm{~S}_{11}$ separator as shown in Figure 1b. The top-view (Figure 4c-e) and cross-section (Figure S10) EDS mapping of $\mathrm{P}$ and $\mathrm{S}$ shows that these two elements are homogeneously distributed in the film. The ion-conductive ability of the coating is examined by comparing the impedance spectra of the coated and uncoated $\mathrm{Li}_{7} \mathrm{P}_{3} \mathrm{~S}_{11}$ separators (Figure 4f). The pristine $\mathrm{Li}_{7} \mathrm{P}_{3} \mathrm{~S}_{11}$ separator shows a total resistance of $16 \Omega$, corresponding to an ionic conductivity of $3.5 \times 10^{-3} \mathrm{~S} \mathrm{~cm}^{-1}$. The protective coating results in an additional semicircle in the impedance spectrum which corresponds to the resistance of the coating with the value of $90 \Omega$. Due to the thin thickness of the coating, the resistance increase is fully acceptable and the coated separator still possesses excellent ion-conduction ability.

Additionally, the ion-conductive coating shows good stability and adhesion when the coated separators are used in hybrid Li-S batteries. After 50-cycle operation of the battery, the morphology of the cathode side of the coated separator still keeps its original smooth surface, while the anode side only shows a few etched pits likely due 
to the limited reaction with lithium (Figure S11). It indicates that the protective coating keeps well adhered to the $\operatorname{Li}_{7} \mathrm{P}_{3} \mathrm{~S}_{11}$ separators even under the electrochemical environment in batteries.

Figure 5a-b show the charge-discharge curves of the hybrid batteries with coated and uncoated $\mathrm{Li}_{7} \mathrm{P}_{3} \mathrm{~S}_{11}$ separators. In the hybrid battery with coated $\mathrm{Li}_{7} \mathrm{P}_{3} \mathrm{~S}_{11}$ separator, the voltage of the $2^{\text {nd }}$ discharge plateau is well kept at $2.10 \mathrm{~V}$ and the charge plateau at 2.28 $\mathrm{V}$ during the 50 cycles (Figure 5a), showing an excellent cycling stability. Without coating, the overpotential of the battery quickly increases during the charge-discharge cycling (Figure 5b). The improvement of operational stability is also demonstrated by comparing the impedance spectra of the two batteries at different charge/discharge depths. The internal resistance of the battery with uncoated SE separator varies largely during operation (Figure S14b). In contrast, the internal resistance of the battery with coated SE separator is almost unchanged at different charge/discharge depths (Figure S14d), resulting in flat charge/discharge plateaus.

The pristine sulfur-carbon composite cathode shows porous morphology which is constructed by nanoparticles of ketjen black (Figure 5c). The morphology of the cathodes disassembled from the hybrid Li-S batteries after 50 cycles is reexamined. In the battery with coated $\mathrm{Li}_{7} \mathrm{P}_{3} \mathrm{~S}_{11}$ separator, the porous cathode structure is visibly unchanged (Figure 5d), while in the battery with uncoated $\mathrm{Li}_{7} \mathrm{P}_{3} \mathrm{~S}_{11}$ separator, a continuous thin layer is formed on the porous cathode after cycling (Figure 5e). The thin layer could passivate the reactive sites of the cathode. Consequently, the 
overpotential of the battery increases and the capacity decreases. With the $\beta$ - $\mathrm{Li}_{3} \mathrm{PS}_{4}-$ based coating on $\mathrm{Li}_{7} \mathrm{P}_{3} \mathrm{~S}_{11}$ separator, the formation of passivation layer on cathode is inhibited, improving therefore the cycling stability.

EDS mapping of the passivation layer on cathode reveals that it is rich of $\mathrm{S}$ and $\mathrm{P}$ (Figure 5f-i). Taking into account that $\mathrm{P}$ only exists in the SE separator in the pristine battery, it can be concluded that the passivation layer is a decomposition product of the separator. XPS was further used to determine the chemical environment of the elements. One main $\mathrm{P}_{2 \mathrm{p} 3 / 2}$ peak with binding energy around $134.3 \mathrm{eV}$ can be observed in the $\mathrm{P}_{2 p}$ spectrum (Figure 5j), corresponding to $\mathrm{P}$ linked with bridging sulfur in $\mathrm{P}^{*} \mathrm{~S}-$ structure. ${ }^{40}$ In the $\mathrm{S}_{2 \mathrm{p}}$ spectrum, two main $\mathrm{S}_{2 \mathrm{p} 3 / 2}$ peaks at $169.6 \mathrm{eV}$ and $164.1 \mathrm{eV}$ and a minor $\mathrm{S}_{2 \mathrm{p} 3 / 2}$ peak at $167.4 \mathrm{eV}$ are observed (Figure 5k), attributed respectively to $\mathrm{S}^{*} \mathrm{O}_{2} \mathrm{CF}_{3}$ from the salt LiTFSI, ${ }^{64}$ to bridging sulfur in $\mathrm{S}-\mathrm{S}^{*}-\mathrm{S}$ or $\mathrm{P}-\mathrm{S}^{*}-\mathrm{P}$ structures ${ }^{65-66}$ and to $\mathrm{Lix}_{\mathrm{x}} \mathrm{S}^{*} \mathrm{O}_{\mathrm{y}}$ or $-\mathrm{S}^{*} \mathrm{O}_{2} \mathrm{CF}_{2}{ }^{+}$trace. ${ }^{28}$ It is worth noting that the XPS signals belonging to $\mathrm{Li}_{2} \mathrm{~S}\left(\mathrm{~S}_{2 \mathrm{p} 3 / 2} \text { at } 160.0 \mathrm{eV}\right)^{65,67}$ and $\mathrm{P}-\mathrm{S}$ tetrahedral anions such as $\mathrm{PS}_{4}{ }^{3-}\left(\mathrm{P}_{2 \mathrm{p} 3 / 2}\right.$ at 133.6 and $132.6 \mathrm{eV}, \mathrm{S}_{2 \mathrm{p} 3 / 2}$ at $162.5 \mathrm{eV}$ and $\left.161.6 \mathrm{eV}\right)^{40}$ are absent. Therefore, the passivation layer on cathode is not formed by direct dissolution of the SE separator which contains P-S tetrahedral anions, but by the delithiated species, rich in P-S-P bridging sulfur structure (Figure S16). 

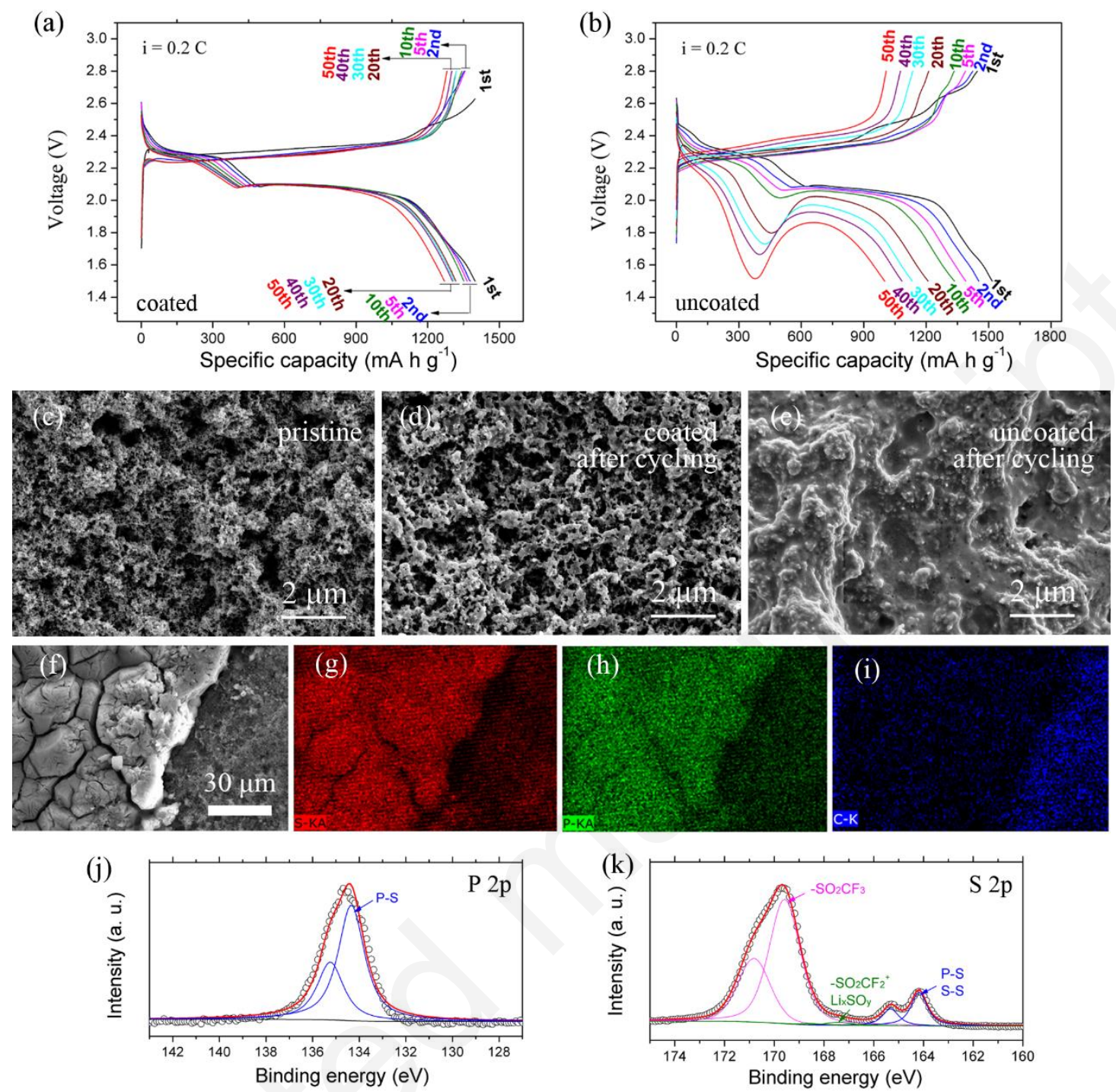

Figure 5. Improved cycling stability of the hybrid battery by $\beta-\mathrm{Li}_{3} \mathrm{PS}_{4} / \mathrm{S}$ coated solid

electrolyte. Charge-discharge curves at $0.2 \mathrm{C}$ rate of the hybrid Li-S batteries (a) with coated

$\mathrm{Li}_{7} \mathrm{P}_{3} \mathrm{~S}_{11}$ separator and (b) uncoated $\mathrm{Li}_{7} \mathrm{P}_{3} \mathrm{~S}_{11}$ separator. SEM images of S-C composite cathode (c)

before cycling and disassembled from the hybrid Li-S batteries with (d) coated and (e) uncoated

$\mathrm{Li}_{7} \mathrm{P}_{3} \mathrm{~S}_{11}$ separators after 50 cycles. (f-i) EDS mapping and (j-k) XPS profiles of the passivation

layer on the cathode of the battery with uncoated $\mathrm{Li}_{7} \mathrm{P}_{3} \mathrm{~S}_{11}$ separator. 
Finally, the mechanism how $\beta$ - $\mathrm{Li}_{3} \mathrm{PS}_{4}$-based coating on the $\mathrm{Li}_{7} \mathrm{P}_{3} \mathrm{~S}_{11}$ separator improves the cycling performance of hybrid Li-S batteries is proposed in Figure 6 . Without $\beta$ - $\mathrm{Li}_{3} \mathrm{PS}_{4}$ coating, the $\mathrm{Li}_{7} \mathrm{P}_{3} \mathrm{~S}_{11}$ separator is decomposed, in contact with the ether-based liquid electrolyte, into DME-solvated $\mathrm{Li}_{3} \mathrm{PS}_{4}$ and an amorphous phase containing vertex-shared $\mathrm{PS}_{4}$ tetrahedral anions. The amorphous phase is partially dissolved and diffuses onto the cathode. It is further delithiated, resulting in the formation of a poorly conductive passivation layer rich of $\mathrm{P}-\mathrm{S}-\mathrm{P}$ bridging sulfur structure. This layer passivates the reactive sites of the cathode so the performance of the battery degrades progressively. Differently, even though $\beta-\mathrm{Li}_{3} \mathrm{PS}_{4}$ also reacts with the ether-based liquid electrolyte, the only product, DME-solvated $\mathrm{Li}_{3} \mathrm{PS}_{4}$, is insoluble and prevents further solvation of $\beta-\mathrm{Li}_{3} \mathrm{PS}_{4}$. Consequently, the $\mathrm{Li}_{7} \mathrm{P}_{3} \mathrm{~S}_{11}$ separator coated with $\beta$ - $\mathrm{Li}_{3} \mathrm{PS}_{4}$ produces few soluble products which can be deposited on the cathode and the cycling performance of the battery is therefore greatly improved.

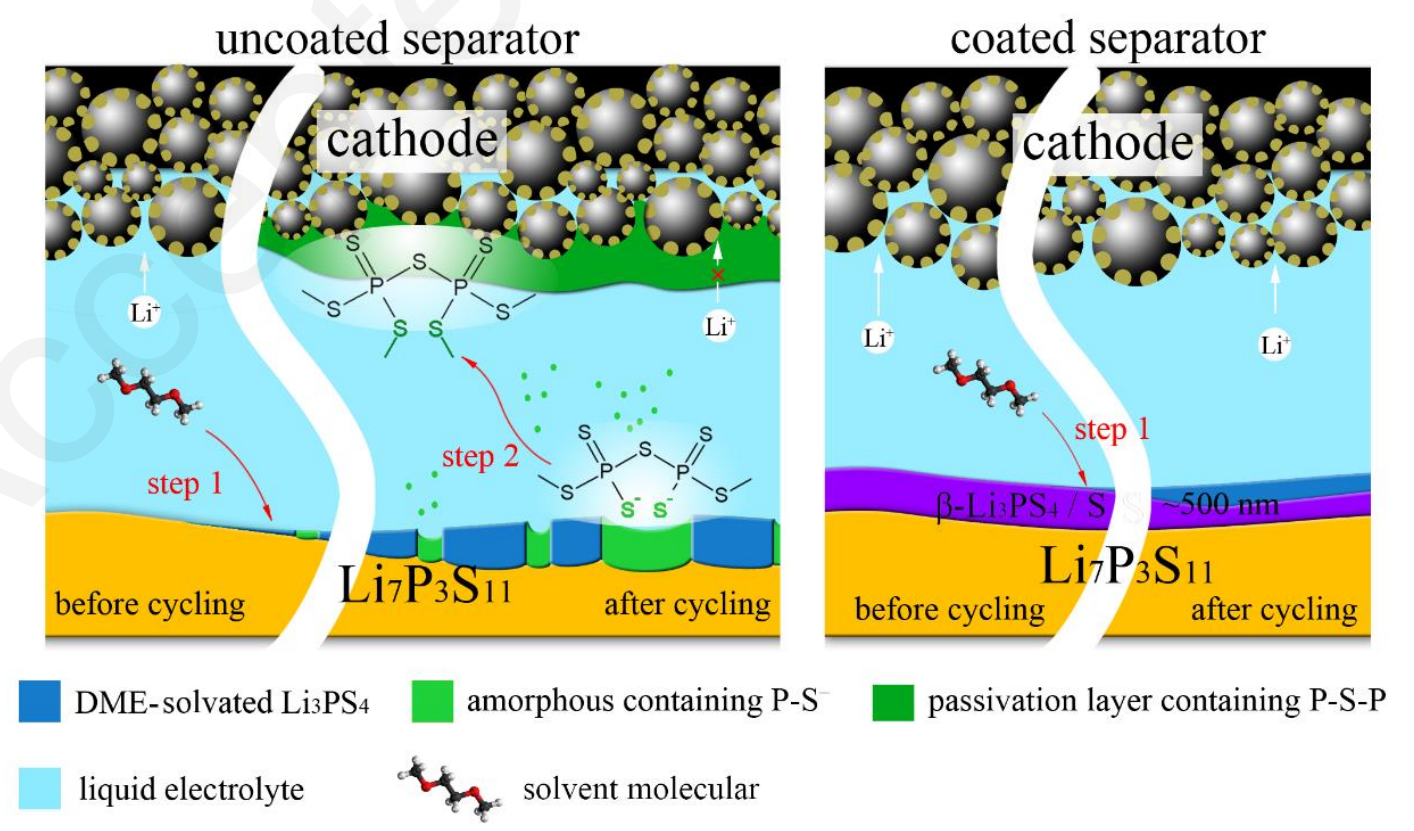


Figure 6. Proposed mechanism for the improved cycling performance by $\beta$ - $\mathrm{Li}_{3} \mathrm{PS}_{4}$-based

coating. Without coating, Step 1: $\mathrm{Li}_{7} \mathrm{P}_{3} \mathrm{~S}_{11}$ reacts with the solvent, decomposed into DME-

complexed $\mathrm{Li}_{3} \mathrm{PS}_{4}$ and an amorphous containing vertex-shared $\mathrm{PS}_{4}$ tetrahedral anions; Step 2: The anions diffuse to the cathode, delithiated to form a layer rich of P-S-P structure that passivates the reactive sites. With coating, a continuous insoluble DME-complexed $\mathrm{Li}_{3} \mathrm{PS}_{4}$ layer is formed to

prevent further reaction.

\section{Hybrid Li-S batteries by stable sulfide electrolyte/liquid interface}

The $\beta$ - $\mathrm{Li}_{3} \mathrm{PS}_{4}$ coated $\mathrm{Li}_{7} \mathrm{P}_{3} \mathrm{~S}_{11}$ composite separators possess not only good interfacial stability with ether-based solvents, but also good ion conduction ability due to the high ionic conductivity of sulfide SEs. Therefore, good cycling stability and redox kinetics are expected to be simultaneously achieved when applying these composite separators in hybrid Li-S batteries.

Figure 7 compares the performance of hybrid Li-S batteries with sulfide SE separator and liquid Li-S batteries. Three batteries are studied, one with uncoated $\mathrm{Li}_{7} \mathrm{P}_{3} \mathrm{~S}_{11}$ separator, another one with $\beta-\mathrm{Li}_{3} \mathrm{PS}_{4}$ coated $\mathrm{Li}_{7} \mathrm{P}_{3} \mathrm{~S}_{11}$ separator and the reference one with commercial polymer separator Celgard $\mathbb{R}$ 2400. All these batteries use a commercial ether-based electrolyte (1M LiTFSI DME/DOL (50-50 vol\%)-1\% $\mathrm{LiNO}_{3}$ ) to wet the electrodes or the separator. The battery with coated SE separator shows an initial discharge capacity of $1399 \mathrm{~mA} \mathrm{~h} \mathrm{~g}^{-1}$ at $0.2 \mathrm{C}$ rate $\left(1 \mathrm{C}=1675 \mathrm{~mA} \mathrm{~g}^{-1}\right)$. The specific capacity remains $1270 \mathrm{~mA} \mathrm{~h} \mathrm{~g}^{-1}$ after 50 cycles. Similar initial discharge capacities are achieved in the battery with uncoated SE separator $\left(1517 \mathrm{~mA} \mathrm{~h} \mathrm{~g}^{-1}\right)$ or 
the liquid battery $\left(1231 \mathrm{~mA} \mathrm{~h} \mathrm{~g}^{-1}\right)$ at the same rate, but the discharge capacities are quickly deteriorated to $1000 \mathrm{~mA} \mathrm{~h} \mathrm{~g}^{-1}$ and to $818 \mathrm{~mA} \mathrm{~h} \mathrm{~g}^{-1}$ respectively after 50 cycles. The better capacity retention of the hybrid batteries than the liquid battery is attributed to the inhibition of shuttle effect. As shown in Figure $7 \mathrm{~b}$, the coulombic efficiency of the two hybrid batteries reaches $100 \%$ after first few cycles, indicating the migration of the soluble polysulfide has been totally prevented. ${ }^{23}$ As for the liquid battery, its coulombic efficiency firstly increases to $99.3 \%$ after few cycles then gradually decreases to $96.1 \%$ after 50 cycles. Even though the liquid electrolyte additive $\mathrm{LiNO}_{3}$ can somehow attenuate polysulfide shuttling by the formation of a solid-stateelectrolyte-interphase (SEI) film on lithium, ${ }^{63-68}$ the in-situ formed SEI film suffers from repeated breaking and repairing during the charge-discharge process. ${ }^{42}$ Therefore, the shuttling cannot be thoroughly prevented and the coulombic efficiency gradually decreases due to the degradation of the SEI film.

Figure 7c shows the initial charge-discharge curves of the liquid battery and the hybrid battery with $\beta$-Li3 $\mathrm{PS}_{4}$ coated $\mathrm{Li}_{7} \mathrm{P}_{3} \mathrm{~S}_{11}$ separator. The overpotential between the $0.2 \mathrm{C}$ charge and discharge curves of the hybrid battery is only $180 \mathrm{mV}$, at the same level with the liquid Li-S battery. The small overpotential favours high-rate operation of the battery. As shown in Figure $7 d$, the hybrid battery retains a specific capacity of $945 \mathrm{~mA} \mathrm{~h} \mathrm{~g}^{-1}$ at $1.5 \mathrm{C}$-rate charge/discharge, showing better rate capacity than the liquid battery. 

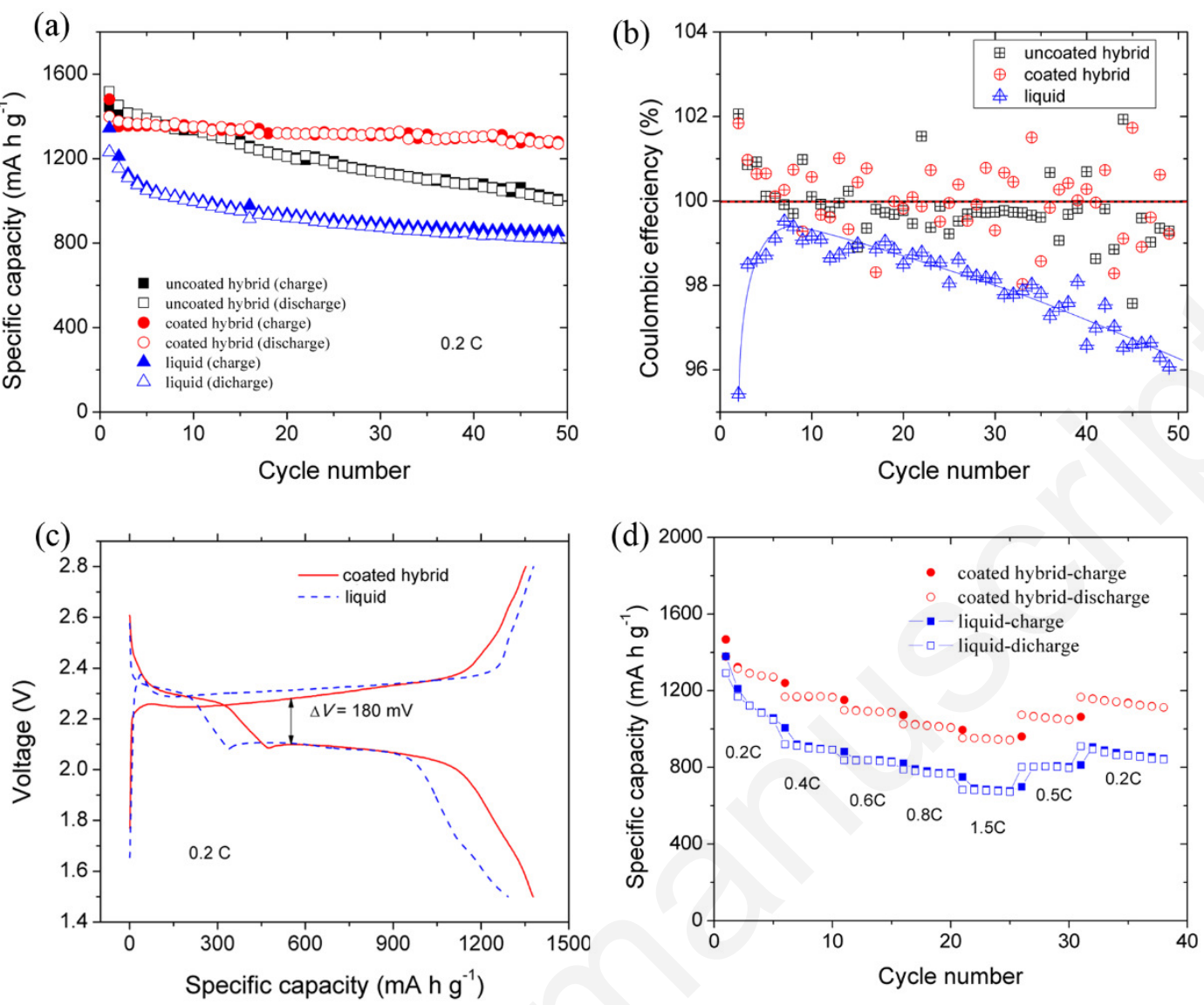

Figure 7. Comparison of the performance between hybrid Li-S batteries with sulfide SE

separator and liquid Li-S batteries. (a) cycling performance at $0.2 \mathrm{C}$ rate; (b) coulombic efficiency; (c) initial charge-discharge curves at $0.2 \mathrm{C}$ rate and $(\mathrm{d})$ rate performance.

To further demonstrate the cycling stability with the $\beta$ - $\mathrm{Li}_{3} \mathrm{PS}_{4}$ coated $\mathrm{Li}_{7} \mathrm{P}_{3} \mathrm{~S}_{11}$ separator, a Celgard ${ }^{\circledR} 2400$ separator wetted by $1 \mathrm{M}$ LiTFSI DOL- $1 \% \mathrm{LiNO}_{3}$ has been inserted between the SE separator and the lithium anode so that accidental short circuit of the batteries due to lithium penetration can be avoided. The cell stably operates 150 cycles at $0.2 \mathrm{C}$ rate, retaining $1047 \mathrm{~mA} \mathrm{~h} \mathrm{~g}^{-1}$ at the end (Figure 8a). Especially after the $100^{\text {th }}$ cycle, a very low average capacity decay rate of $0.06 \% /$ cycle is achieved, demonstrating the excellent cycling stability of the battery. Its coulombic efficiency is 


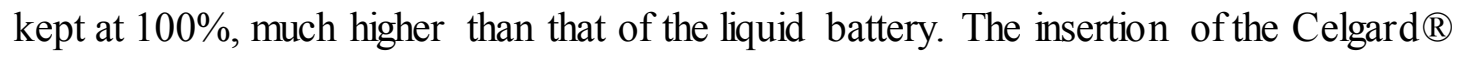
2400 slightly lowers the discharge plateau due to the increase of interfacial resistance, but the $2^{\text {nd }}$ discharge plateau still reaches $2.06 \mathrm{~V}$ even after 150 cycles (Figure $8 \mathrm{~b}$ ). This cycling stability is better than the reported hybrid Li-S batteries directedly using oxide solid-electrolyte separators such LAGP $\left(1528 \mathrm{~mA} \mathrm{~h} \mathrm{~g}^{-1}\right.$ to $720 \mathrm{~mA} \mathrm{~h} \mathrm{~g}{ }^{-1}$ during 40 cycles at $0.2 \mathrm{C}$ rate) and LLZO (1154 $\mathrm{mA} \mathrm{h} \mathrm{g}^{-1}$ to $604 \mathrm{~mA} \mathrm{~h} \mathrm{~g}-1$ during 50 cycles at $0.06 \mathrm{C}$ rate), ${ }^{23,33}$ and is comparable with the hybrid Li-S batteries with interfacial engineered NASICON-type solid-electrolyte separators. ${ }^{31-32}$ This is ascribed to the absent of high-valence metal ions $\left(\mathrm{Ti}^{4+}, \mathrm{Ge}^{4+}\right.$, etc. $)$ in $\mathrm{Li}_{2} \mathrm{~S}-\mathrm{P}_{2} \mathrm{~S}_{5}$ glass-ceramic solid electrolyte, and to the insoluble dense solvated $\mathrm{Li}_{3} \mathrm{PS}_{4}$ layer at the solid/liquid electrolyte interface. Considering the high ionic conductivity of sulfide electrolytes that favors the redox kinetics of batteries, we propose that sulfide electrolytes with delicate composition design are competitive candidates for constructing stable solid-liquidelectrolyte interface.

(a)

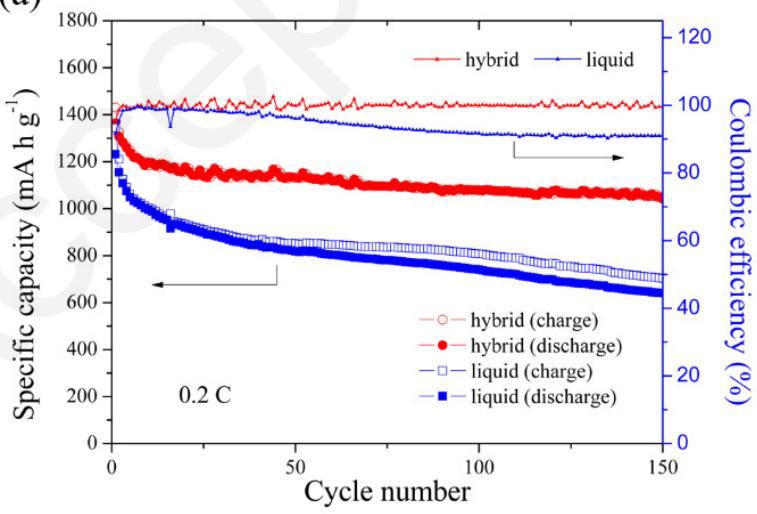

(b)

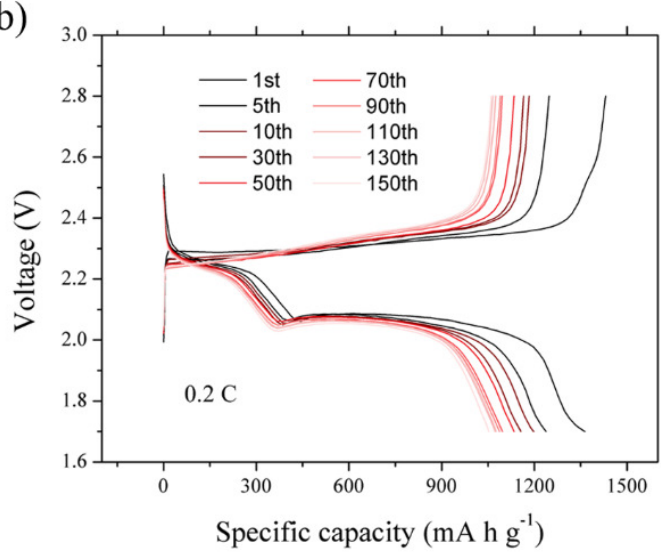


Figure 8. Cycling stability demonstrated by a hybrid Li-S battery with an anti-lithiumpenetration design. (a) cycling performance and (b) charge-discharge curves at $0.2 \mathrm{C}$ rate, in comparison with a liquid battery.

Finally, we emphasize that the interfacial stability between $\beta-\mathrm{Li}_{3} \mathrm{PS}_{4}$ and the etherbased electrolytes is only kinetically achieved. In fact, the formation of a thin dense interphase layer of insoluble solvated $\mathrm{Li}_{3} \mathrm{PS}_{4}$ is essential for the interfacial stability. Therefore, absolute chemical stability with liquid electrolytes is not an indispensable prerequisite for a good SE separator. This concept opens a new path to improve the stability of sulfide/liquid electrolyte interface by tuning the microstructure and the composition of the solvated interphase layer to make it thinner, denser and more ionconductive. Here we propose several possible approaches. First, considering the insoluble nature is a prerequisite for forming a stable interphase layer, tuning the solubility of the solvated phase by appropriate component design of the liquid electrolyte could be an effective way to optimize the microstructure of the interphase layer. Second, limiting the crystal size of the solvated interphase is beneficial to the density of the layer, which might be achieved by adding ligand molecules into the liquid electrolyte or by electrochemical methods.

\section{CONCLUSIONS}

We demonstrate that sulfide solid-electrolyte separators based on $\mathrm{Li}_{2} \mathrm{~S}_{-} \mathrm{P}_{2} \mathrm{~S}_{5}$ glassceramics can be used to develop conversion-type batteries with simultaneously good stability and excellent redox kinetics, as shown by a hybrid lithium-sulfur battery which 
conserves a high discharge capacity of $1047 \mathrm{~mA} \mathrm{~h} \mathrm{~g}^{-1}$ and a high $2^{\text {nd }}$ discharge plateau of $2.06 \mathrm{~V}$ after 150 cycles. The excellent properties of the $\mathrm{Li}_{2} \mathrm{~S}_{-}-\mathrm{P}_{2} \mathrm{~S}_{5}$ glass-ceramics based separator originate not only from its high ionic conductivity, but also from the surprisingly high interfacial stability between $\beta$-Lis $\mathrm{PS}_{4}$ and ether-based liquid electrolyte under both reduction and oxidization conditions in the battery. This interfacial stability is closely associated with the formation of a thin dense solvated $\mathrm{Li}_{3} \mathrm{PS}_{4}$ protective layer, which is insoluble in the ether solvent and which do not compromise the high ionic conductivity of the $\mathrm{Li}_{7} \mathrm{P}_{3} \mathrm{~S}_{11}$ solid electrolyte. This discovery brings in new insight on the stability of solid/liquid electrolyte interface, and may open a new path to improve the stability/cyclability of high energy density batteries by tuning the solubility and microstructure of the solvated interphase layer.

\section{ASSOCIATED CONTENT}

Supporting Information. The support information is available free of charge.

Details about the dual-solution-mixing route for preparing $\beta$-Lis $\mathrm{PS}_{4} / \mathrm{S}$ composite; Phase structure analysis during the dual-solution-mixing route; Impedance spectra and EDS mappings of the solvated lithium thiophosphates; XPS spectra of the lithium anodes dissembled from the $\mathrm{Li} / \mathrm{Li}$ symmetric cells after cycling; Supplementary characterizations of the $\beta$ - $\mathrm{Li}_{3} \mathrm{PS}_{4}$-based coating and its influence on the electrochemical stability of the solid/liquid electrolyte interface; Impedance spectra of the hybrid batteries at different charge/discharge depths; Scheme of a possible route for the formation of the passivation layer on the cathode.

Notes. The authors declare no competing financial interest.

\section{ACKNOWLEGEMENT}


This work is the financially supported by the National Natural Science

Foundation of China (No.51702216), the Natural Science Foundation of Guangdong

Province (No. 2017A030313325/2020A1515011430), the Shenzhen Science and

Technology Foundation (JCYJ20180507182106754), and the Shenzhen Key Lab

Fund (ZDSYS20170228105421966).

\section{REFERENCES}

1. Li, M.; Lu, J.; Chen, Z.; Amine, K., 30 Years of Lithium-Ion Batteries. Adv. Mater. 2018, 30, 1800561.

2. Kato, Y.; Hori, S.; Saito, T.; Suzuki, K.; Hirayama, M.; Mitsui, A.; Yonemura, M.; Iba, H.; Kanno, R., High-Power All-Solid-State Batteries Using Sulfide

Superionic Conductors. Nat. Energy 2016, 1, 16030.

3. Janek, J.; Zeier, W. G., A Solid Future for Battery Development. Nat. Energy 2016, $1,16141$.

4. Muldoon, J.; Bucur, C. B.; Gregory, T., Quest for Nonaqueous Multivalent Secondary Batteries: Magnesium and Beyond. Chem. Rev. 2014, 114, 11683-11720.

5. Aurbach, D.; Lu, Z.; Schechter, A.; Gofer, Y.; Gizbar, H.; Turgeman, R.; Cohen, Y.; Moshkovich, M.; Levi, E., Prototype Systems for Rechargeable Magnesium Batteries. Nature 2000, 407, 724-727.

6. Hakari, T.; Hayashi, A.; Tatsumisago, M., Li2S-Based Solid Solutions as Positive Electrodes with Full Utilization and Superlong Cycle Life in All-Solid-State Li/S Batteries. Adv. Sustainable Systems 2017, 1, 1700017.

7. Wang, Y.; Liu, T.; Estevez, L.; Kumar, J., Kinetics of All-Solid-State Sulfur Cathodes. Energy Storage Mater. 2020, 27, 232-243.

8. Rauh, R. D.; Abraham, K. M.; Pearson, G. F.; Surprenant, J. K.; Brummer, S. B., A Lithium/Sissolved Sulfur Battery with an Organic Electrolyte. J. Electrochem. Soc. 1979, 126, 523-527.

9. Bruce, P. G.; Freunberger, S. A.; Hardwick, L. J.; Tarascon, J.-M., Li-O 2 and LiS Batteries with High Energy Storage. Nat. Mater. 2012, 11, 19-29.

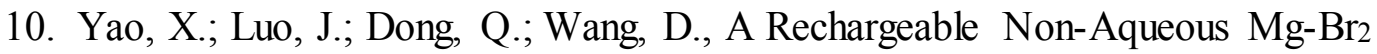
Battery. Nano Energy 2016, 28, 440-446.

11. Tian, H.; Gao, T.; Li, X.; Wang, X.; Luo, C.; Fan, X.; Yang, C.; Suo, L.; Ma, Z.; Han, W., Wang, C., High Power Rechargeable Magnesium/Iodine Battery Chemistry. Nat. Comm. 2017, 8, 14083. 
12. Zhao-Karger, Z.; Liu, R.; Dai, W.; Li, Z.; Diemant, T.; Vinayan, B. P.; Bonatto Minella, C.; Yu, X.; Manthiram, A.; Behm, R. J., Ruben, M,; Fichtner, M., Toward Highly Reversible Magnesium-Sulfur Batteries with Efficient and Practical $\mathrm{Mg}\left[\mathrm{B}(\mathrm{hfip})_{4}\right]_{2}$ Electrolyte. ACS Energy Lett. 2018, 3, 2005-2013.

13. Cohn, G.; Ma, L.; Archer, L. A., A Novel Non-Aqueous Aluminum Sulfur Battery. J. Power Sources 2015, 283, 416-422.

14. Mikhaylik, Y. V.; Akridge, J. R., Polysulfide Shuttle Study in the Li/S Battery System. J. Electrochem. Soc. 2004, 151, A1969-A1976.

15. Manthiram, A.; Fu, Y.; Su, Y.-S., Challenges and Prospects of Lithium-Sulfur Batteries. Acc. Chem. Res. 2013, 46, 1125-1134.

16. Ren, W.; Ma, W.; Zhang, S.; Tang, B., Recent Advances in Shuttle Effect Inhibition for Lithium Sulfur Batteries. Energy Storage Mater. 2019, 23, 707-732.

17. Pang, Q.; Kundu, D.; Cuisinier, M.; Nazar, L. F., Surface-Enhanced Redox Chemistry of Polysulphides on a Metallic and Polar Host for Lithium-Sulphur Batteries. Nat. Comm. 2014, 5, 4759.

18. Ma, G.; Wen, Z.; Jin, J.; Lu, Y.; Wu, X.; Wu, M.; Chen, C., Hollow Polyaniline Sphere@Sulfur Composites for Prolonged Cycling Stability of Lithium-Sulfur Batteries. J. Mater. Chem. A 2014, 2, 10350-10354.

19. Wei Seh, Z.; Li, W.; Cha, J. J.; Zheng, G.; Yang, Y.; McDowell, M. T.; Hsu, P.C.; Cui, Y., Sulphur-TiO 2 Yolk-Shell Nanoarchitecture with Internal Void Space for Long-Cycle Lithium-Sulphur Batteries. Nat. Comm. 2013, 4, 1331.

20. Zhao, C.-Z.; Cheng, X.-B.; Zhang, R.; Peng, H.-J.; Huang, J.-Q.; Ran, R.; Huang, Z.-H.; Wei, F.; Zhang, Q., Li2 $\mathrm{S}_{5}$-Based Ternary-Salt Electrolyte for Robust Lithium Metal Anode. Energy Storage Mater. 2016, 3, 77-84.

21. Barghamadi, M.; Best, A. S.; Bhatt, A. I.; Hollenkamp, A. F.; Musameh, M.; Rees, R. J.; Rüther, T., Lithium-Sulfur Batteries - the Solution is in the Electrolyte, but is the Electrolyte a Solution? Energy Environ. Sci. 2014, 7, 3902-3920.

22. Yu, X.; Bi, Z.; Zhao, F.; Manthiram, A., Hybrid Lithium-Sulfur Batteries with a Solid Electrolyte Membrane and Lithium Polysulfide Catholyte. ACS Appl. Mater. Interfaces 2015, 7, 16625-16631.

23. Wang, Q.; Jin, J.; Wu, X.; Ma, G.; Yang, J.; Wen, Z., A Shuttle Effect Free Lithium Sulfur Battery Based on a Hybrid Electrolyte. Phys. Chem. Chem. Phys. 2014, 16, 21225-21229.

24. Manthiram, A.; Li, L., Hybrid and Aqueous Lithium-Air Batteries. Adv. Energy Mater. 2015, 5, 1401302.

25. Son, S.-B.; Gao, T.; Harvey, S. P.; Steirer, K. X.; Stokes, A.; Norman, A.; Wang, C.; Cresce, A.; Xu, K.; Ban, C., An Artificial Interphase Enables Reversible Magnesium Chemistry in Carbonate Electrolytes. Nat. Chem. 2018, 10, 532-539.

26. Wang, L.; Wang, Y.; Xia, Y., A High Performance Lithium-Ion Sulfur Battery Based on a $\mathrm{Li}_{2} \mathrm{~S}$ Cathode Using a Dual-Phase Electrolyte. Energy Environ. Sci. 2015, $8,1551-1558$.

27. Sun, Y., Lithium Ion Conducting Membranes for Lithium-Air Batteries. Nano Energy 2013, 2, 801-816. 
28. Busche, M. R.; Drossel, T.; Leichtweiss, T.; Weber, D. A.; Falk, M.; Schneider, M.; Reich, M.-L.; Sommer, H.; Adelhelm, P.; Janek, J., Dynamic Formation of a Solid-Liquid Electrolyte Interphase and its Consequences for Hybrid-Battery Concepts. Nat. Chem. 2016, 8, 426-434.

29. Wang, S.; Ding, Y.; Zhou, G.; Yu, G.; Manthiram, A., Durability of the $\mathrm{Li}_{1+\mathrm{x}} \mathrm{Ti}_{2}$ ${ }_{x} \mathrm{Al}_{\mathrm{x}}\left(\mathrm{PO}_{4}\right)_{3}$ Solid Electrolyte in Lithium-Sulfur Batteries. ACS Energy Lett. 2016, 1 , 1080-1085.

30. Gu, S.; Huang, X.; Wang, Q.; Jin, J.; Wang, Q.; Wen, Z.; Qian, R., A Hybrid Electrolyte for Long-Life Semi-Solid-State Lithium Sulfur Batteries. J. Mater. Chem. A 2017, 5, 13971-13975.

31. Yu, X.; Bi, Z.; Zhao, F.; Manthiram, A., Polysulfide-Shuttle Control in LithiumSulfur Batteries with a Chemically/Electrochemically Compatible NaSICON-type Solid Electrolyte. Adv. Energy Mater. 2016, 6, 1601392.

32. Yu, X.; Manthiram, A., Enhanced Interfacial Stability of Hybrid-Electrolyte Lithium-Sulfur Batteries with a Layer of Multifunctional Polymer with Intrinsic Nanoporosity. Adv. Funct. Mater. 2019, 29, 1805996.

33. Naguib, M.; Sharafi, A.; Self, E. C.; Meyer, H. M.; Sakamoto, J.; Nanda, J., Interfacial Reactions and Performance of $\mathrm{Li}_{7} \mathrm{La}_{3} \mathrm{Zr}_{2} \mathrm{O}_{12}$-Stabilized Li-Sulfur Hybrid Cell. ACS Appl. Mater. Interfaces 2019, 11, 42042-42048.

34. Seino, Y.; Ota, T.; Takada, K.; Hayashi, A.; Tatsumisago, M., A Sulphide Lithium Super ion Conductor is Superior to Liquid Ion Conductors for Use in Rechargeable Batteries. Energy Environ. Sci. 2014, 7, 627-631.

35. Kamaya, N.; Homma, K.; Yamakawa, Y.; Hirayama, M.; Kanno, R.; Yonemura, M.; Kamiyama, T.; Kato, Y.; Hama, S.; Kawamoto, K., Mitsui, Akio, A Lithium Superionic Conductor. Nat. Mater. 2011, 10, 682-686.

36. Philip, M. A.; Sullivan, P. T.; Zhang, R.; Wooley, G. A.; Kohn, S. A.; Gewirth, A. A., Improving Cell Resistance and Cycle Life with Solvate-Coated Thiophosphate Solid Electrolytes in Lithium Batteries. ACS Appl. Mater. Interfaces 2019, 11, 20142021.

37. Oh, D. Y.; Nam, Y. J.; Park, K. H.; Jung, S. H.; Cho, S.-J.; Kim, Y. K.; Lee, Y.G.; Lee, S.-Y.; Jung, Y. S., Excellent Compatibility of Solvate Ionic Liquids with Sulfide Solid Electrolytes: Toward Favorable Ionic Contacts in Bulk-Type All-SolidState Lithium-Ion Batteries. Adv. Energy Mater. 2015, 5, 1500865.

38. Lin, Z.; Liu, Z.; Fu, W.; Dudney, N. J.; Liang, C., Phosphorous Pentasulfide as a Novel Additive for High-Performance Lithium-Sulfur Batteries. Adv. Funct. Mater. 2013, 23, 1064-1069.

39. Pang, Q.; Liang, X.; Shyamsunder, A.; Nazar, L. F., An in vivo Formed Solid Electrolyte Surface Layer Enables Stable Plating of Li Metal. Joule 2017, 1, 871-886. 40. Liang, J.; Li, X.; Zhao, Y.; Goncharova, L. V.; Wang, G.; Adair, K. R.; Wang, C.; Li, R.; Zhu, Y.; Qian, Y., Zhang, L.; Yang, R.; Lu, S.; Sun, X., In situ Li3PS4 SolidState Electrolyte Protection Layers for Superior Long-Life and High-Rate LithiumMetal Anodes. Adv. Mater. 2018, 30, 1804684. 
41. Lu, Y.; Gu, S.; Hong, X.; Rui, K.; Huang, X.; Jin, J.; Chen, C.; Yang, J.; Wen, Z., Pre-Modified $\mathrm{Li}_{3} \mathrm{PS}_{4}$ Based Interphase for Lithium Anode Towards HighPerformance Li-S Battery. Energy Storage Mater. 2018, 11, 16-23.

42. Xiong, S.; Xie, K.; Diao, Y.; Hong, X., Characterization of the Solid Electrolyte Interphase on Lithium Anode for Preventing the Shuttle Mechanism in LithiumSulfur Batteries. J. Power Sources 2014, 246, 840-845.

43. Hayashi, A.; Hama, S.; Minami, T.; Tatsumisago, M., Formation of Superionic Crystals from Mechanically Milled $\mathrm{Li}_{2} \mathrm{~S}-\mathrm{P}_{2} \mathrm{~S}_{5}$ Glasses. Electrochem. Commun. 2003, $5,111-114$.

44. Chen, S.; Xie, D.; Liu, G.; Mwizerwa, J. P.; Zhang, Q.; Zhao, Y.; Xu, X.; Yao, X., Sulfide Solid Electrolytes for All-Solid-State Lithium Batteries: Structure, Conductivity, Stability and Application. Energy Storage Mater. 2018, 14, 58-74. 45. Xue, B.; Fan, B.; Li, B.; Chen, L.; Wang, F.; Luo, Z.; Zhang, X.; Ma, H., Solvent-Assisted Ball Milling for Synthesizing Solid Electrolyte $\operatorname{Li}_{7} \mathrm{P}_{3} \mathrm{~S}_{11}$. J. Am. Ceram. Soc. 2019, 102, 3402-3410.

46. Ito, S.; Nakakita, M.; Aihara, Y.; Uehara, T.; Machida, N., A Synthesis of Crystalline $\mathrm{Li}_{7} \mathrm{P}_{3} \mathrm{~S}_{11}$ Solid Electrolyte from 1,2-Dimethoxyethane Solvent. J. Power Sources 2014, 271, 342-345.

47. Wang, Y.; Lu, D.; Bowden, M.; El Khoury, P. Z.; Han, K. S.; Deng, Z. D.; Xiao, J.; Zhang, J.-G.; Liu, J., Mechanism of Formation of $\mathrm{Li}_{7} \mathrm{P}_{3} \mathrm{~S}_{11}$ Solid Electrolytes through Liquid Phase Synthesis. Chem. Mater. 2018, 30, 990-997. 48. Fan, B.; Zhang, Q.; Luo, Z.; Zhang, X.; Ma, H.; Fan, P.; Xue, B., Influence of Precipitate/Supernatant Ratio during Liquid-Phase Synthesis of Solid Electrolyte $\mathrm{Li}_{7} \mathrm{P}_{3} \mathrm{~S}_{11}$. Solid State Ionics 2019, 343, 115073.

49. Weiss, M.; Seidlhofer, B.-K.; Geiß, M.; Geis, C.; Busche, M. R.; Becker, M.; Vargas-Barbosa, N. M.; Silvi, L.; Zeier, W. G.; Schröder, D., Janek, J., Unraveling the Formation Mechanism of Solid-Liquid Electrolyte Interphases on LiPON Thin Films. ACS Appl. Mater. Interfaces 2019, 11, 9539-9547.

50. Wang, Z.; Jiang, Y.; Wu, J.; Jiang, Y.; Huang, S.; Zhao, B.; Chen, Z.; Zhang, J., Reaction Mechanism of $\mathrm{Li}_{2} \mathrm{~S}-\mathrm{P}_{2} \mathrm{~S}_{5}$ System in Acetonitrile Based on Wet Chemical Synthesis of $\mathrm{Li}_{7} \mathrm{P} 3 \mathrm{~S}_{11}$ Solid Electrolyte. Chem. Eng. J. 2020, 393, 124706.

51. Wang, H.; Hood, Z. D.; Xia, Y.; Liang, C., Fabrication of Ultrathin Solid Electrolyte Membranes of $\beta$ - $\mathrm{Li}_{3} \mathrm{PS}_{4}$ Nanoflakes by Evaporation-Induced SelfAssembly for All-Solid-State Batteries. J. Mater. Chem. A 2016, 4, 8091-8096. 52. Liu, Z.; Fu, W.; Payzant, E. A.; Yu, X.; Wu, Z.; Dudney, N. J.; Kiggans, J.; Hong, K.; Rondinone, A. J.; Liang, C., Anomalous High Ionic Conductivity of Nanoporous $\beta$-Li3 PS4. J. Am. Chem. Soc. 2013, 135, 975-978.

53. Krauskopf, T.; Richter, F. H.; Zeier, W. G.; Janek, J., Physicochemical Concepts of the Lithium Metal Anode in Solid-State Batteries. Chem. Rev. 2020.

54. Porz, L.; Swamy, T.; Sheldon, B. W.; Rettenwander, D.; Frömling, T.; Thaman, H. L.; Berendts, S.; Uecker, R.; Carter, W. C.; Chiang, Y.-M., Mechanism of Lithium Metal Penetration through Inorganic Solid Electrolytes. Adv.Energy Mater. 2017, 7, 1701003. 
55. Xu, R.; Han, F.; Ji, X.; Fan, X.; Tu, J.; Wang, C., Interface Engineering of Sulfide Electrolytes for All-Solid-State Lithium Batteries. Nano Energy 2018, 53, 958-966.

56. Kzzlaslan, A.; Çetinkaya, T.; Akbulut, H., 2H-MoS 2 as an Artificial Solid Electrolyte Interface in All-Solid-State Lithium-Sulfur Batteries. Adv. Mater. Interfaces 2020, 7, 2001020.

57s.Lee, Y.-G.; Fujiki, S.; Jung, C.; Suzuki, N.; Yashiro, N.; Omoda, R.; Ko, D.-S.;

Shiratsuchi, T.; Sugimoto, T.; Ryu, S., Ku, J.; Watanabe, T.; Park, Y.; Aihara, Y.; Im, D.; Han, I.T., High-Energy Long-Cycling All-Solid-State Lithium Metal Batteries Enabled by Silver-Carbon Composite Anodes. Nat. Energy 2020, 5, 299-308.

58. Yersak, T. A.; Salvador, J. R.; Pieczonka, N. P. W.; Cai, M., Dense, Melt Cast Sulfide Glass Electrolyte Separators for Li Metal Batteries. J. Electrochem. Soc. 2019, 166, A1535-A1542.

59. Zhu, Y.; He, X.; Mo, Y., Origin of Outstanding Stability in the Lithium Solid Electrolyte Materials: Insights from Thermodynamic Analyses Based on FirstPrinciples Calculations. ACS Appl. Mater. Interfaces 2015, 7, 23685-23693.

60. Li, M.; Bai, Z.; Li, Y.; Ma, L.; Dai, A.; Wang, X.; Luo, D.; Wu, T.; Liu, P.; Yang, L., Amine, K.; Chen, Z.; Lu, J., Electrochemically Primed Functional Redox Mediator Generator from the Decomposition of Solid State Electrolyte. Nat. Comm. 2019, 10, 1890.

61. Hayashi, A.; Minami, K.; Mizuno, F.; Tatsumisago, M., Formation of $\mathrm{Li}^{+}$ Superionic Crystals from the $\mathrm{Li}_{2} \mathrm{~S}-\mathrm{P}_{2} \mathrm{~S}_{5}$ Melt-Quenched Glasses. J. Mater. Sci. 2008, 43, 1885-1889.

62. Ohtomo, T.; Hayashi, A.; Tatsumisago, M.; Tsuchida, Y.; Hama, S.; Kawamoto, K., All-Solid-State Lithium Secondary Batteries Using the $75 \mathrm{Li}_{2} \mathrm{~S} \cdot 25 \mathrm{P}_{2} \mathrm{~S}_{5}$ Glass and the $70 \mathrm{Li}_{2} \mathrm{~S} \cdot 30 \mathrm{P}_{2} \mathrm{~S}_{5}$ Glass-Ceramic as Solid Electrolytes. J. Power Sources 2013, 233, 231-235.

63. Miura, A.; Rosero-Navarro, N. C.; Sakuda, A.; Tadanaga, K.; Phuc, N. H. H.; Matsuda, A.; Machida, N.; Hayashi, A.; Tatsumisago, M., Liquid-Phase Syntheses of Sulfide Eectrolytes for All-Solid-State Lithium Battery. Nat. Rev. Chem. 2019, 3, 189-198.

64. Zheng, J.; Gu, M.; Chen, H.; Meduri, P.; Engelhard, M. H.; Zhang, J.-G.; Liu, J.; Xiao, J., Ionic Liquid-Enhanced Solid State Electrolyte Interface (SEI) for LithiumSulfur Batteries. J. Mater. Chem. A 2013, 1, 8464-8470.

65. Tanibata, N.; Tsukasaki, H.; Deguchi, M.; Mori, S.; Hayashi, A.; Tatsumisago, M., A Novel Discharge-Charge Mechanism of a S- $\mathrm{P}_{2} \mathrm{~S}_{5}$ Composite Electrode without Electrolytes in All-Solid-State Li/S Batteries. J. Mater. Chem. A 2017, 5, 1122411228.

66. Dietrich, C.; Koerver, R.; Gaultois, M. W.; Kieslich, G.; Cibin, G.; Janek, J.; Zeier, W. G., Spectroscopic Characterization of Lithium Thiophosphates by XPS and XAS - A Model to Help Monitor Interfacial Reactions in All-Solid-State Batteries. Phys. Chem. Chem. Phys. 2018, 20, 20088-20095.

67. Aurbach, D.; Pollak, E.; Elazari, R.; Salitra, G.; Kelley, C. S.; Affinito, J., On the Surface Chemical Aspects of Very High Energy Density, Rechargeable Li-Sulfur Batteries. J. Electrochem. Soc. 2009, 156, A694-A702. 
68. Liang, X.; Wen, Z.; Liu, Y.; Wu, M.; Jin, J.; Zhang, H.; Wu, X., Improved Cycling Performances of Lithium Sulfur Batteries with $\mathrm{LiNO}_{3}$-Modified Electrolyte. J. Power Sources 2011, 196, 9839-9843. 